\author{
UnB - UNIVERSIDADE DE BRASÍLIA \\ FGA - FACULDADE GAMA \\ PROGRAMA DE PÓS-GRADUAÇÃO EM ENGENHARIA \\ BIOMÉDICA
}

Sistema Informatizado de Gestão de Tecnologia em

Estabelecimentos de Assistência à Saúde

ANTONIO DOMINGUES NETO

ORIENTADOR: Dr. José Felício da Silva

DISSERTAÇÃO DE MESTRADO EM ENGENHARIA BIOMÉDICA

PUBLICAÇÃO: 066A / 2017

BRASÍLIA/DF: Março - 2017 


\section{UNIVERSIDADE DE BRASÍLIA \\ FACULDADE GAMA \\ ENGENHARIA BIOMÉDICA}

\section{SISTEMA INFORMATIZADO DE GESTÃO DE TECNOLOGIA EM ESTABELECIMENTOS DE ASSISTÊNCIA À SAÚDE}

\section{ANTONIO DOMINGUES NETO}

DISSERTAÇÃO DE MESTRADO SUBMETIDA À FACULDADE UNB GAMA DA UNIVERSIDADE DE BRASÍLIA, COMO PARTE DOS REQUISITOS NECESSÁRIOS PARA A OBTENÇÃO DO GRAU DE MESTRE EM ENGENHARIA BIOMÉDICA.

APROVADA POR:

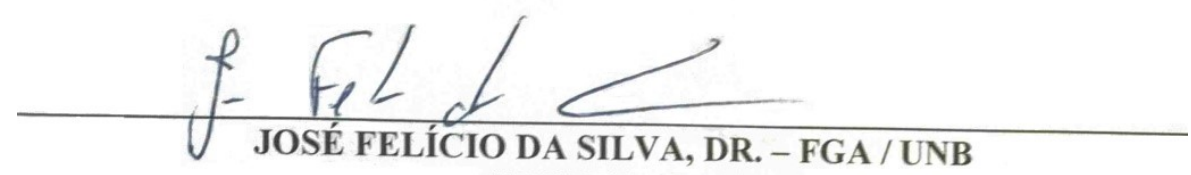
(ORIENTADOR)

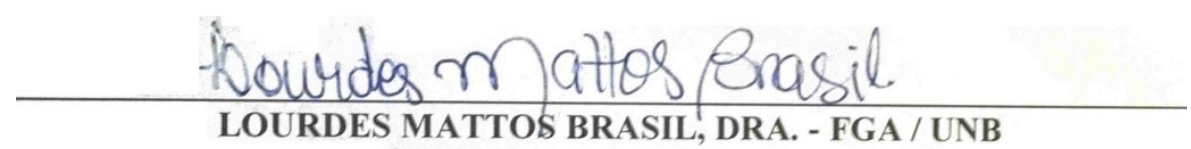
(EXAMINADOR INTERNO)

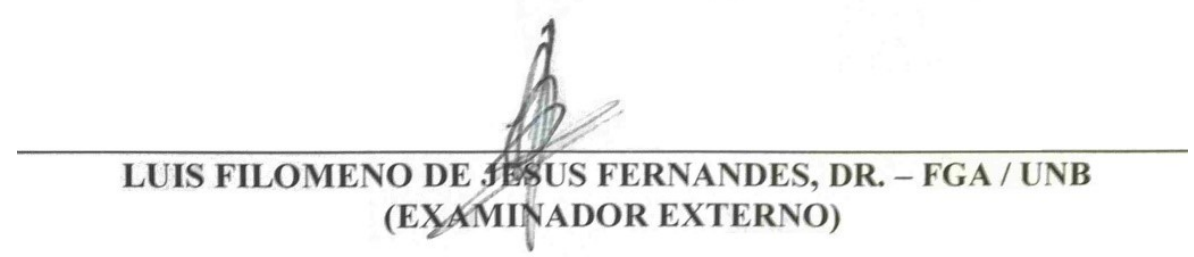

BRASÍLIA/DF, 30 DE MARÇO DE 2017. 


\section{FICHA CATALOGRÁFICA}

\section{DOMINGUES NETO, ANTONIO}

Sistema informatizado de gestão de tecnologia em Estabelecimentos de Assistência à Saúde, [Distrito Federal] 2017.

65.p., 210 x 297 mm (FGA/UnB Gama, Mestre, Engenharia Biomédica, 2017). Dissertação de Mestrado - Universidade de Brasília. Faculdade Gama. Programa de Pós-Graduação em Engenharia Biomédica.

1. SISTEMA DE GESTÃO 2. TECNOLOGIA EM SAÚDE

3. DESENVOLVIMENTO $W E B$

I. FGA UnB Gama/ UnB. II. Título (série)

\section{REFERÊNCIA BIBLIOGRÁFICA}

DOMINGUES NETO, A. (2017). TÍTULO. Dissertação de Mestrado em Engenharia Biomédica, Publicação 066A/2017, Programa de Pós-Graduação em Engenharia Biomédica, Faculdade Gama, Universidade de Brasília, Brasília, DF, 70.p.

\section{CESSÃO DE DIREITOS}

AUTOR: ANTONIO DOMINGUES NETO.

TÍTULO: Sistema informatizado de gestão de tecnologia em Estabelecimentos de Assistência à Saúde

GRAU: Mestre

ANO: 2017

É concedida à Universidade de Brasília permissão para reproduzir cópias desta dissertação de mestrado e para emprestar ou vender tais cópias somente para propósitos acadêmicos e científicos. $\mathrm{O}$ autor reserva outros direitos de publicação e nenhuma parte desta dissertação de mestrado pode ser reproduzida sem a autorização por escrito do autor.

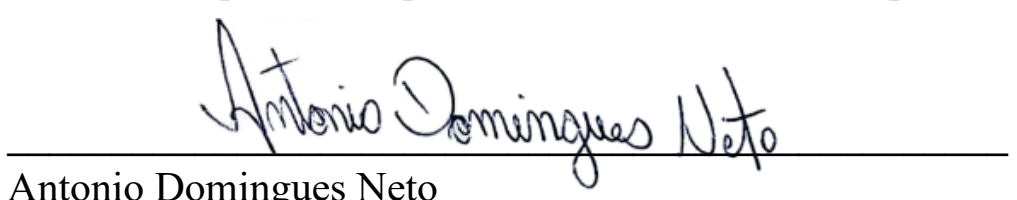

Antonio Domingues Neto

SQS 204 Bloco K Apto 205 - Asa Sul.

CEP 70234-110 Brasília, DF - Brasil. 


\section{DEDICATÓRIA}

Para os verdadeiros amigos,

O mundo é um lugar perigoso de se viver, não por causa daqueles que fazem o mal, mas sim por causa daqueles que observam e deixam o mal acontecer.

Albert Einstein. 


\section{AGRADECIMENTOS}

Aos alunos e amigos do curso de Pós-Graduação em Engenharia Biomédica da Universidade de Brasília (UnB), da Faculdade Gama (FGA), que todos nós possamos corresponder às necessidades que esta área da Engenharia, tão importante para a sociedade, requer para oferecer melhores condições a todos.

Aos professores que possibilitaram a assimilação de novos conhecimentos, abrindo novos horizontes e maiores possibilidades.

Aos meus pais (Adejaime e Marta), irmãos (Amarildo, Maria Marta e José Carlos) e amigos que sempre me incentivam, rezaram e estiveram ao meu lado dando muita força e energia para a conclusão deste trabalho. 
RESUMO

\title{
SISTEMA INFORMATIZADO DE GESTÃO DE TECNOLOGIA EM ESTABELECIMENTOS DE ASSISTÊNCIA À SAÚDE
}

\author{
Autor: ANTONIO DOMINGUES NETO \\ Orientador: Prof. Dr. José Felício da Silva \\ Programa de Pós-Graduação em Engenharia Biomédica
}

Brasília, Março de 2017.

O gerenciamento dos Equipamentos Médico-Hospitalares (EMH) é de vital importância para os Estabelecimentos Assistenciais de Saúde (EAS), especialmente para atender as diretrizes da legislação e órgãos reguladores, minimizando os riscos para os pacientes, usuários e meio ambiente. Uma gestão adequada dos EMH reduz os custos, permite melhor controle e planejamento dos EAS. Este trabalho apresenta o estudo e a implementação de um sistema Web para gestão de EMH, visando oferecer recursos para que o maior número de EAS possa adotar a gestão dos EMH. Para validar a proposta desse sistema, foi realizado um estudo de caso em conjunto com um EAS, onde foi possível verificar que a utilização de um sistema específico para EMH melhora o processo de gestão.

Palavras-chaves: Sistema de Gestão; Tecnologia em Saúde; Desenvolvimento Web. 


\title{
ABSTRACT \\ COMPUTER SYSTEM OF TECHNOLOGY MANAGEMENT IN HEALTH CARE INSTITUTION
}

\section{Author: ANTONIO DOMINGUES NETO}

\author{
Supervisor: Prof. Dr. José Felício da Silva
}

\section{Post-Graduation Program in Biomedical Engineering}

\section{Brasília, March of 2017.}

The management of Medical Equipment (ME) is of vital importance to the Health Care Services (HCS). The management of $M E$ is especially important to comply with the guidelines of the law and regulators, and it reduces the risks to patients, the users and the environment. The management of ME reduces costs, allows for a better control and planning of HCS. This work presents a study and implementation of a web system for ME's management. This system aims to provide resources for the greatest number of HCS can adopt the management of the ME. In order to validate the proposal of this system was conducted a case study in HCS, where it was possible to verify that the use of a specific system for ME improves the management process into HCS.

Key-words: System of Management; Technology in Health Care; Web Development. 


\section{SUMÁRIO}

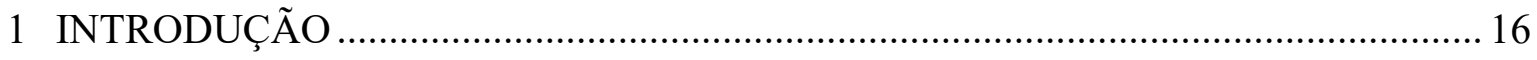

1.1 Contextualização e Formulação do Problema ........................................................... 16

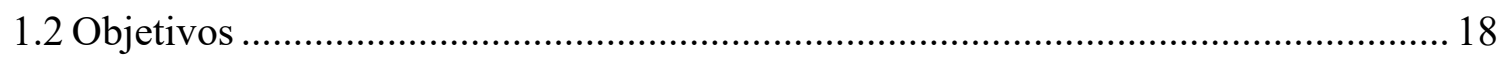

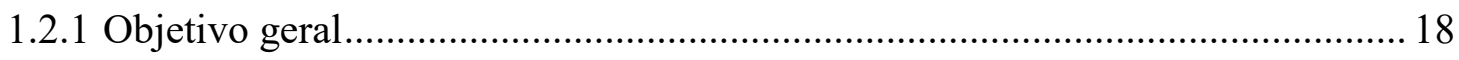

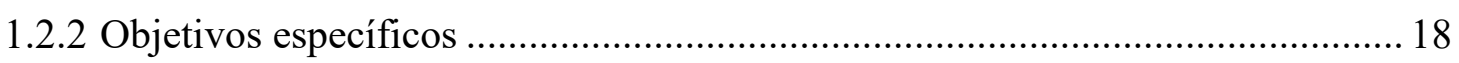

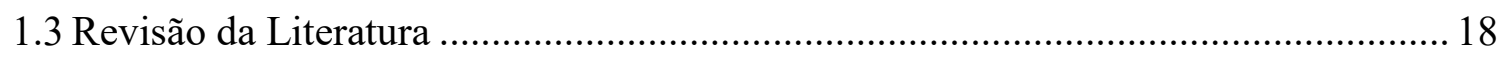

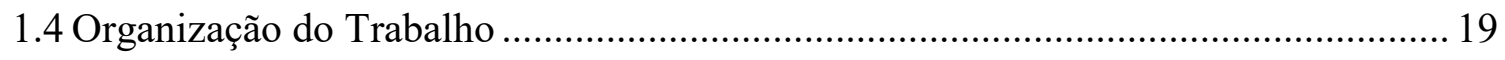

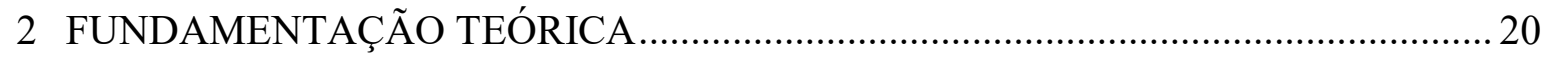

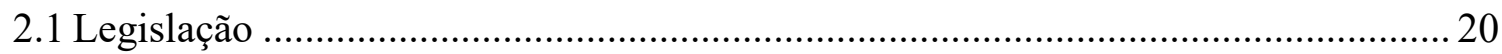

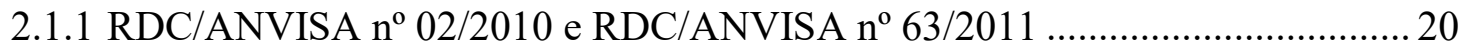

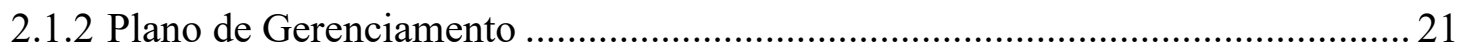

2.2 Processo de Gestão de Tecnologias em Saúde......................................................... 23

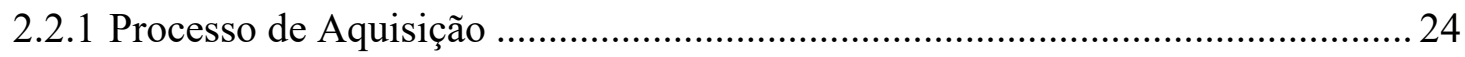

2.2.2 Processo de Aquisição - Levantamento da necessidade e especificação do

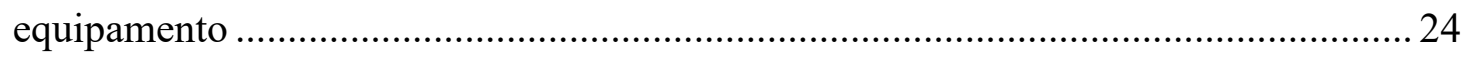

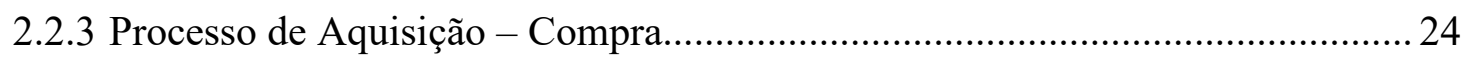

2.2.4 Processo de Aquisição - Recebimento .......................................................... 24

2.2.5 Processo de Aquisição - Instalação ............................................................... 25

2.2.6 Processo de Operação - Levantamento e identificação do parque tecnológico . 25

2.2.7 Processo de Operação - Manutenção preventiva................................................. 25

2.2.8 Processo de Operação - Manutenção corretiva ................................................. 26

2.2.9 Processo de Operação - Calibração ................................................................. 26

2.2.10 Processo de Descarte - Retirada de uso e obsolescência ..............................26

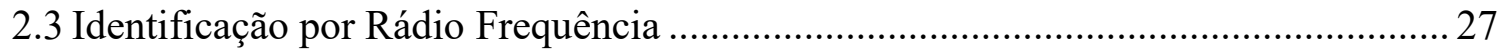

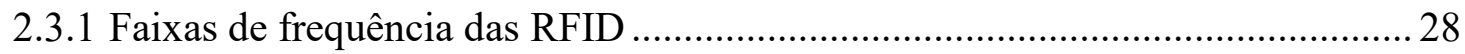

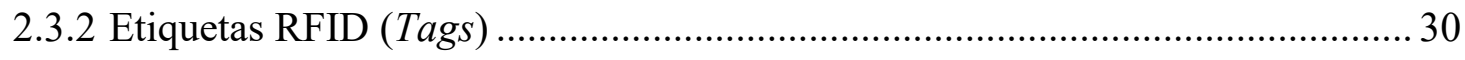


2.3.3 Tipos de Tags RFID

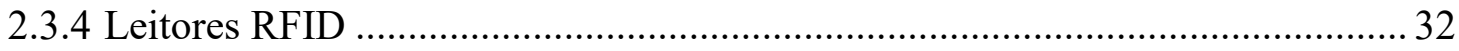

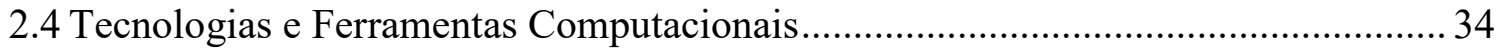

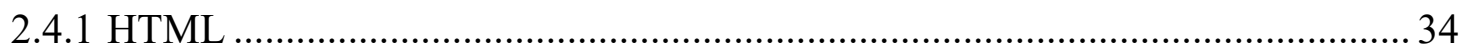

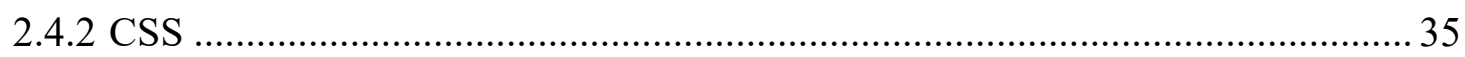

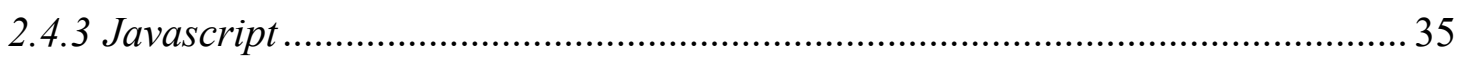

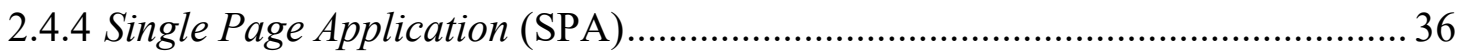

2.4.5 Servidor de Banco de Dados PostgreSQL ......................................................... 37

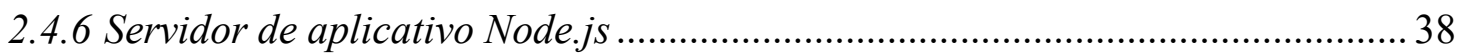

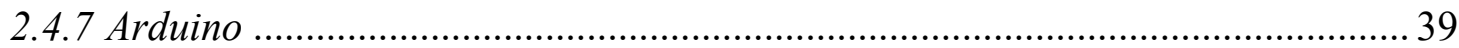

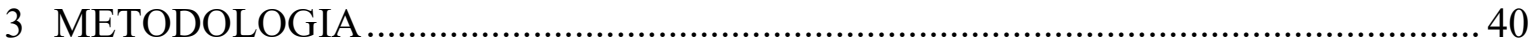

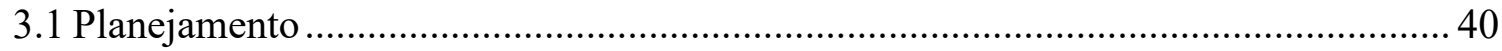

3.1.1 Levantamento de Requisitos ............................................................................ 40

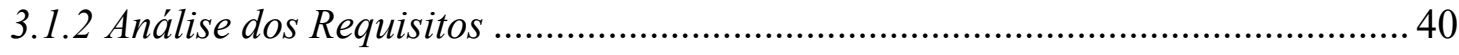

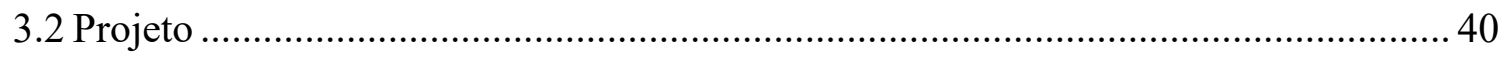

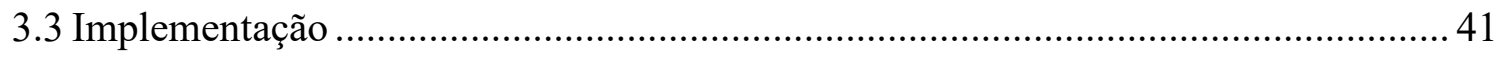

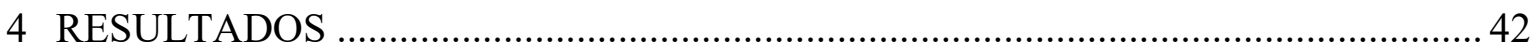

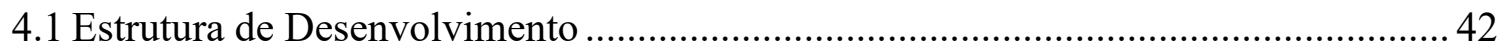

4.1.1 Arquitetura de Desenvolvimento do Sistema ................................................... 42

4.2 Estrutura de Desenvolvimento do Servidor Web ...................................................... 47

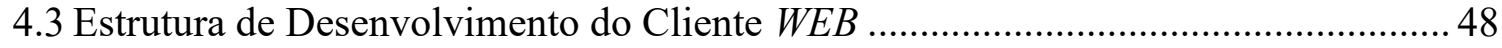

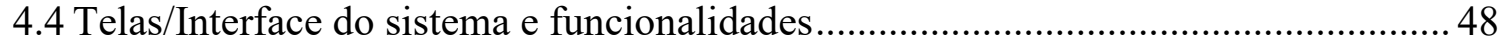

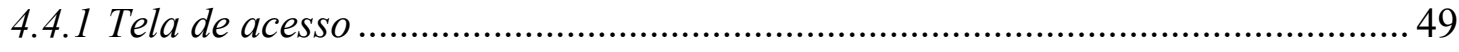

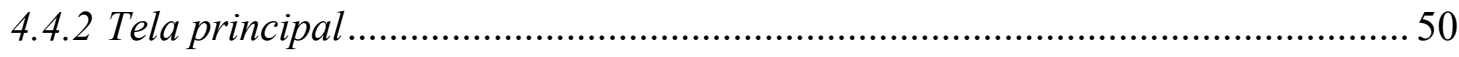

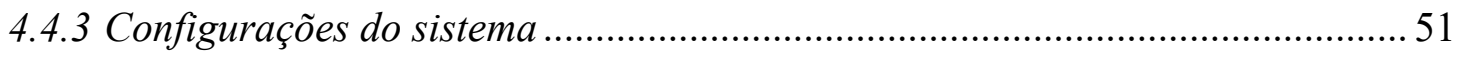

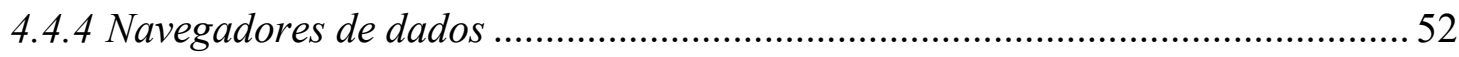

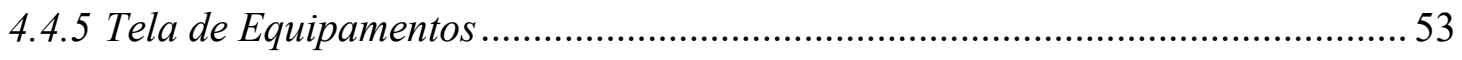




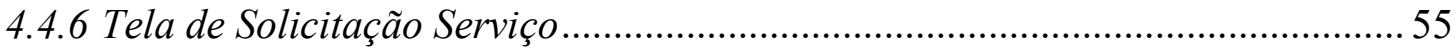

4.4.7 Outras funcionalidades do sistema ..................................................................5 55

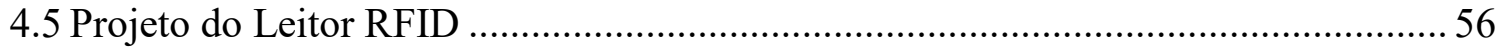

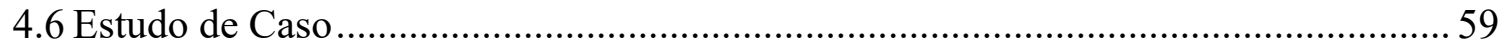

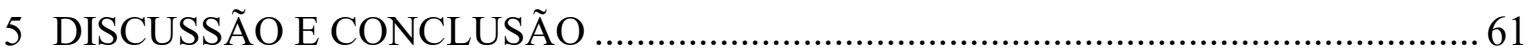

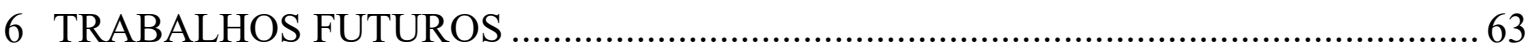

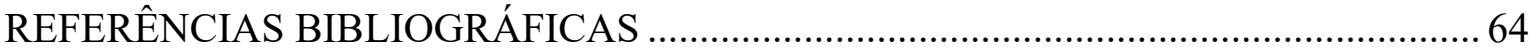

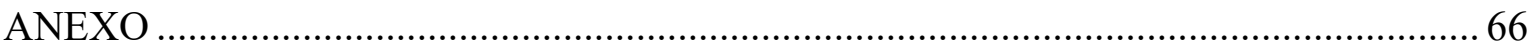

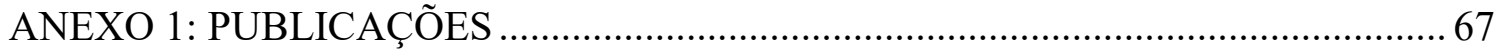




\section{LISTA DE TABELAS}

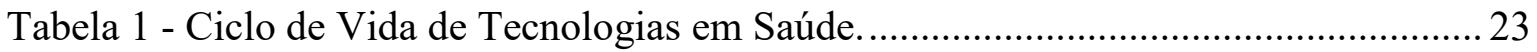

Tabela 2 - Características e aplicações das faixas de frequência populares em RFID ........ 29

Tabela 3 - Grupos funcionais de dados que compõem o sistema...................................... 43

Tabela 4 - Tipos de objetos das entidades do sistema........................................................ 46

Tabela 5 - Lista de componentes do protótipo do Leitor RFID.......................................... 57

Tabela 6 - Equipamentos do EAS (Estudo de Caso) ............................................................. 59

Tabela 7 - Problemas do cadastro dos EMH (Estudo de Caso) ........................................... 59 


\section{LISTA DE FIGURAS}

Figura 1 - Quantidade de EAS por região em março de 2016 (Fonte: CNES).................... 20

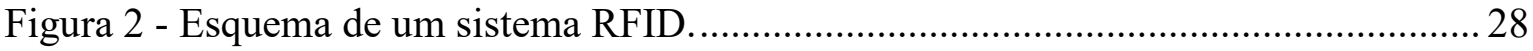

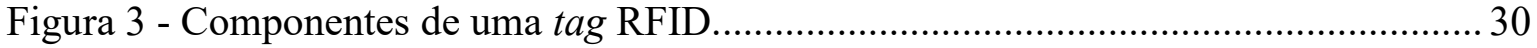

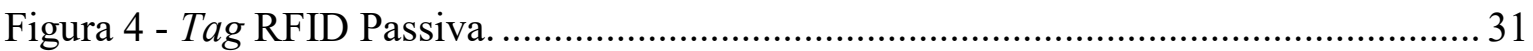

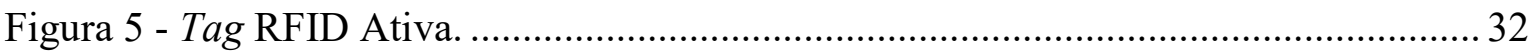

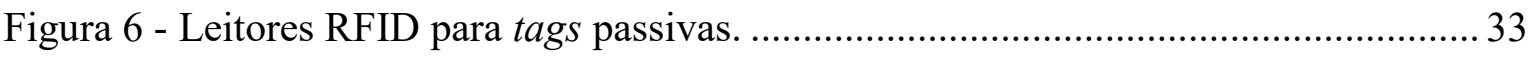

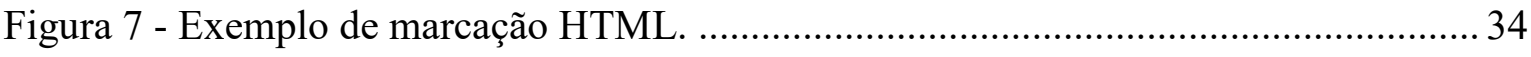

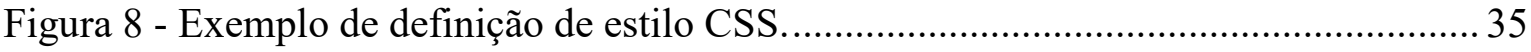

Figura 9 - Esquema de uma aplicação SPA....................................................................... 37

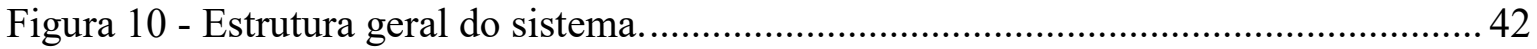

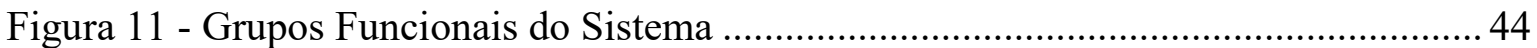

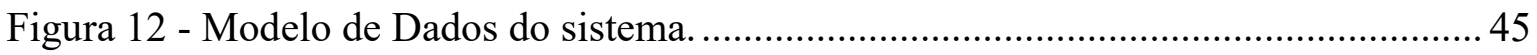

Figura 13 - Fragmento de código da classe Model de Usuário. ......................................... 47

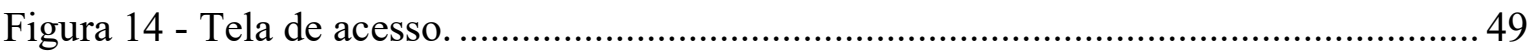

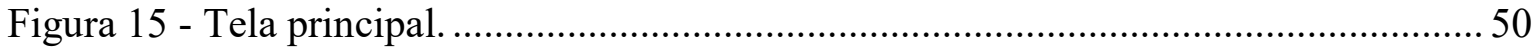

Figura 16 - Tela de configurações do Sistema. .................................................................. 51

Figura 17 - Tela de navegador de dados para Impacto do Defeito..................................... 52

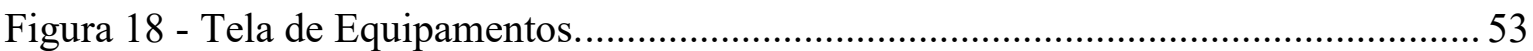

Figura 19 - Associar uma etiqueta RFID a um equipamento......................................... 54

Figura 20 - Tela de Solicitação de Serviço........................................................................... 55

Figura 21 - Protótipo do Leitor RFID com Arduino. ......................................................... 58 


\section{LISTA DE SÍMBOLOS, NOMENCLATURAS E ABREVIAÇÕES}

ACID Atomicidade, Consistência, Integridade e Durabilidade

AJAX Asynchronous Javascript and XML

Javascript Assíncrono e XML

ANSI American National Standards Institute

(Instituto Nacional Americano de Padrões)

ANVISA Agência Nacional de Vigilância Sanitária

API Application Programming Interface

(Interface de Programação de Aplicativos)

CNES Cadastro Nacional de Estabelecimentos de Saúde

CSS Cascading Style Sheets

(Folhas de estilos em Cascata)

DATASUS Departamento de Informática do SUS

DOM Document Object Model

(Modelo de Objeto de Documento)

EAS Estabelecimento de Assistência à Saúde

EAS Estabelecimentos Assistências de Saúde

EC Engenharia Clínica

ECMA European Computer Manufacturers Association

(Associação Europeia de Fabricantes de Computadores)

EMH Equipamentos Médico-Hospitalares

ENSP Escola Nacional de Saúde Pública Sérgio Arouca

FIOCRUZ Fundação Oswaldo Cruz 
GTS Gerenciamento de Tecnologias em Saúde

HF High Frequency

(Alta Frequência)

HTML Hypertext Markup Language

(Linguagem de Marcação de Hipertexto)

ISM Industrial Scientific Medical

(Médico Científico Industrial)

LF

Low Frequency

(Baixa Frequência)

MS Ministério da Saúde

RDC Resolução da Diretoria Colegiada

RF Rádio Frequência

RFID Radio-Frequency IDentification

(Identificação por Rádio Frequência)

SGBD Sistema Gerenciador de Banco de Dados

SPA Single Page Application

(Aplicação de Página Única)

SQL Structured Query Language

(Linguagem Estruturada de Consulta)

SUS Sistema Único de Saúde

TI Tecnologia de Informação

UHF Ultra High Frequency

(Ultra Alta Frequência)

UnB Universidade de Brasília 
USP Universidade de São Paulo

UX User Experience

(Experiência de Usuário)

VHF Very High Frequency

(Frequência Muito Alta)

W3C World Wide Web Consortium

(Consórcio da Rede Mundial de Computadores)

WWW $\quad$ World Wide Web

(Rede Mundial de Computadores) 


\section{INTRODUÇÃO}

\subsection{CONTEXTUALIZAÇÃO E FORMULAÇÃO DO PROBLEMA}

Segundo o Departamento de Informática do Sistema Único de Saúde (DATASUS), o Brasil possui aproximadamente 288 mil Estabelecimentos de Assistência à Saúde (EAS), registrados no Cadastro Nacional de Estabelecimentos de Saúde (CNES), em abril de 2016. Estes EAS apresentam um volume de equipamentos que se divide em 12.703 Equipamentos de Audiologia, 122.973 Equipamentos de Diagnóstico por Imagem, 91.543 Equipamentos de Infraestrutura, 519.935 Equipamentos de Odontologia, 610.368 Equipamentos para Manutenção da Vida, 42.792 Equipamentos por Métodos Gráficos, 62.906 Equipamentos por Métodos Ópticos e 102.094 de Outros Equipamentos, totalizando 1.565.314 equipamentos cadastrados (CNES, 2016). Esta estrutura fornece recursos de saúde para uma população de mais de 200 milhões de brasileiros, apoiada pelos serviços do Sistema Único de Saúde (SUS), gerenciados pelo Ministério da Saúde (MS), e por uma rede de estabelecimentos privados (DATASUS, 2016).

Visando regular os EAS, sobre o ponto de vista do gerenciamento de tecnologia em saúde, o MS por meio da Agência Nacional de Vigilância Sanitária (ANVISA) estabeleceu diversas resoluções que descrevem os requisitos mínimos para o Gerenciamento de Tecnologias em Saúde (GTS). Estes requisitos devem ser adotados pelos EAS na prestação de serviços de saúde, de modo a garantir a sua rastreabilidade, qualidade, eficácia, efetividade e segurança e, no que couber, desempenho, desde a entrada no estabelecimento de saúde até seu destino final, incluindo o planejamento dos recursos físicos, materiais e humanos, bem como, da capacitação dos profissionais envolvidos no processo. Portanto, as resoluções da ANVISA definem que os EAS devem possuir, para execução das atividades de gerenciamento de tecnologias em saúde, normas e rotinas técnicas de procedimentos padronizadas, atualizadas, registradas e acessíveis aos profissionais envolvidos, para cada etapa do gerenciamento (ANVISA, 2010).

Sendo o GTS o conjunto de procedimentos de gestão, planejados e implementados a partir de bases científicas e técnicas, normativas e legais, com o objetivo de garantir a rastreabilidade, qualidade, eficácia, efetividade, segurança e em alguns casos o desempenho das tecnologias de saúde utilizadas na prestação de serviços de saúde (ANVISA, 2010). 
Cada etapa do GTS abrange desde o planejamento e entrada das tecnologias no estabelecimento de saúde até seu descarte, visando à proteção dos trabalhadores, a preservação da saúde pública, a proteção do meio ambiente e a segurança do paciente (ANVISA, 2010).

Uma ferramenta indispensável na implantação do gerenciamento de tecnologias em saúde são os sistemas informatizados, com ferramentas que automatizam várias etapas do processo, fornecendo agilidade, segurança e exatidão das informações. Os sistemas informatizados podem, além de dar suporte ao GTS, auxiliar os gestores nos processos de especificação, aquisição e descartes de produtos e serviços, otimizando a aplicação dos recursos financeiros nos EAS. Outro aspecto importante é que os sistemas informatizados facilitam a manipulação e processamento do grande volume de informações, geradas durante todo o processo.

Tendo em mente a agilidade e a segurança no processo de gestão nos EAS pode ser empregada, em conjunto com os sistemas informatizados, a tecnologia de RadioFrequency IDentification (RFID). Aplicando uma etiqueta RFID em cada equipamento gerenciado é possível rastrear cada item de forma eficiente, reduzir significativamente a mão de obra necessária nessa atividade, além de evitar erros ou até irregularidades que possam ocorrer na gestão do parque tecnológico dos EAS, com uma tecnologia acessível e de fácil utilização.

A partir da coleta e do armazenamento dos dados gerados por sistemas informatizados de GTS, torna-se viável a construção de sistemas de suporte a decisão, comumente conhecidos como Sistemas Inteligentes de Apoio à Decisão, que disponibilizariam aos gestores dos EAS várias informações relevantes para gerenciamento de tecnologias em saúde. Tendo em mente a possibilidade de formação de uma rede de informações sobre gerenciamento de tecnologias em saúde via Web, englobando vários EAS, um Sistema Inteligente de Apoio à Decisão poderia fornecer dados importantes, tais como: custo operacional e de manutenção de um aparelho de determinada marca e modelo, auxiliar na aquisição de equipamentos de acordo com o perfil e demanda dos estabelecimentos, emitir alertas sobre eventos adversos relacionados a produtos e equipamentos, entre outras inúmeras possibilidades. 


\subsection{OBJETIVOS}

\subsubsection{Objetivo geral}

Propor mecanismos que simplifiquem a adoção da GTS pelos EAS.

\subsubsection{Objetivos específicos}

- Fazer uma revisão bibliográfica sobre práticas de GTS nos EAS;

- Desenvolver uma ferramenta informatizada de GTS para padronização de rotinas técnicas de controle e rastreabilidade dos equipamentos médicos hospitalares;

- Propor um controle automatizado para o GTS;

- Fornecer uma infraestrutura que permita a criação de uma rede de informações de tecnologias em saúde nos EAS.

\subsection{REVISÃO DA LITERATURA}

A pesquisa da base bibliográfica utilizada neste trabalho considerou a busca na legislação em vigor no Brasil, que é normatizada pelo MS, além do conteúdo de livros, teses, monografias e artigos publicados anteriormente.

O MS, através da ANVISA, publica diversas normas e leis que regem todos os setores relacionados a produtos e serviços que possam afetar a saúde da população brasileira. Existe um conjunto de normas e leis que tratam especificamente sobre o gerenciamento das tecnologias em saúde, como a RDC/ANVISA n. 02, de 25 de janeiro de 2010, que foi utilizada como referência para desenvolvimento deste trabalho (ANVISA, 2010).

Durante a realização deste trabalho foram utilizados diversos livros como referência, porém verificou-se um número reduzido de publicações nacionais que abordam os assuntos de EC e GTS, principalmente se levado em conta o tamanho do mercado brasileiro. As opções disponíveis são normalmente iniciativas financiadas pelo MS ou vinculadas às universidades, o que leva a refletir que ainda há muito a evoluir na produção de conhecimento nestas áreas. As publicações estrangeiras normalmente abordam a realidade de países europeus ou do mercado norte-americano, com uma abordagem avançada no uso de recursos para GTS, o que nem sempre se aplica na realidade do cenário brasileiro, mas servem de referência do quanto é necessário progredir para alcançar a excelência na GTS. 


\subsection{ORGANIZAÇÃO DO TRABALHO}

Este trabalho está organizado em cinco capítulos, incluindo este capítulo.

No capítulo dois, será apresentada a fundamentação teórica com base no que descreve a legislação, descrição do processo de GTS, ferramentas, padrões e abordagem adotada no desenvolvimento do sistema e uma visão geral da tecnologia RFID que será utilizada na implementação do projeto.

O capítulo três descreve a metodologia utilizada.

No capítulo quatro são apresentados os resultados obtidos.

Por fim, o capítulo cinco discute os pontos de maior importância envolvendo o tema deste estudo, apresenta as conclusões finais do trabalho e os trabalhos futuros, que podem ser desenvolvidos a partir das ideias apresentadas. 


\section{FUNDAMENTAÇÃO TEÓRICA}

\subsection{LEGISLAÇÃO}

Desde o início dos anos 90, o governo do Brasil vem demonstrando preocupação com a qualidade dos produtos e serviços nos EAS. Estas preocupações levaram a definição de leis e diretrizes, que visam normatizar os procedimentos necessários para a gestão dos recursos tecnológicos nos ambientes hospitalares.

\subsubsection{RDC/ANVISA n $n^{0}$ 02/2010 e RDC/ANVISA $n^{0}$ 63/2011}

As definições de políticas públicas de controle se mostram de vital importância, principalmente quando se observa o número de EAS existentes no país. O CNES demonstra que o Brasil apresentava 288.556 estabelecimentos de saúdes, cadastrados em março de 2016, distribuídos por região, conforme Figura 1 (CNES, 2016).

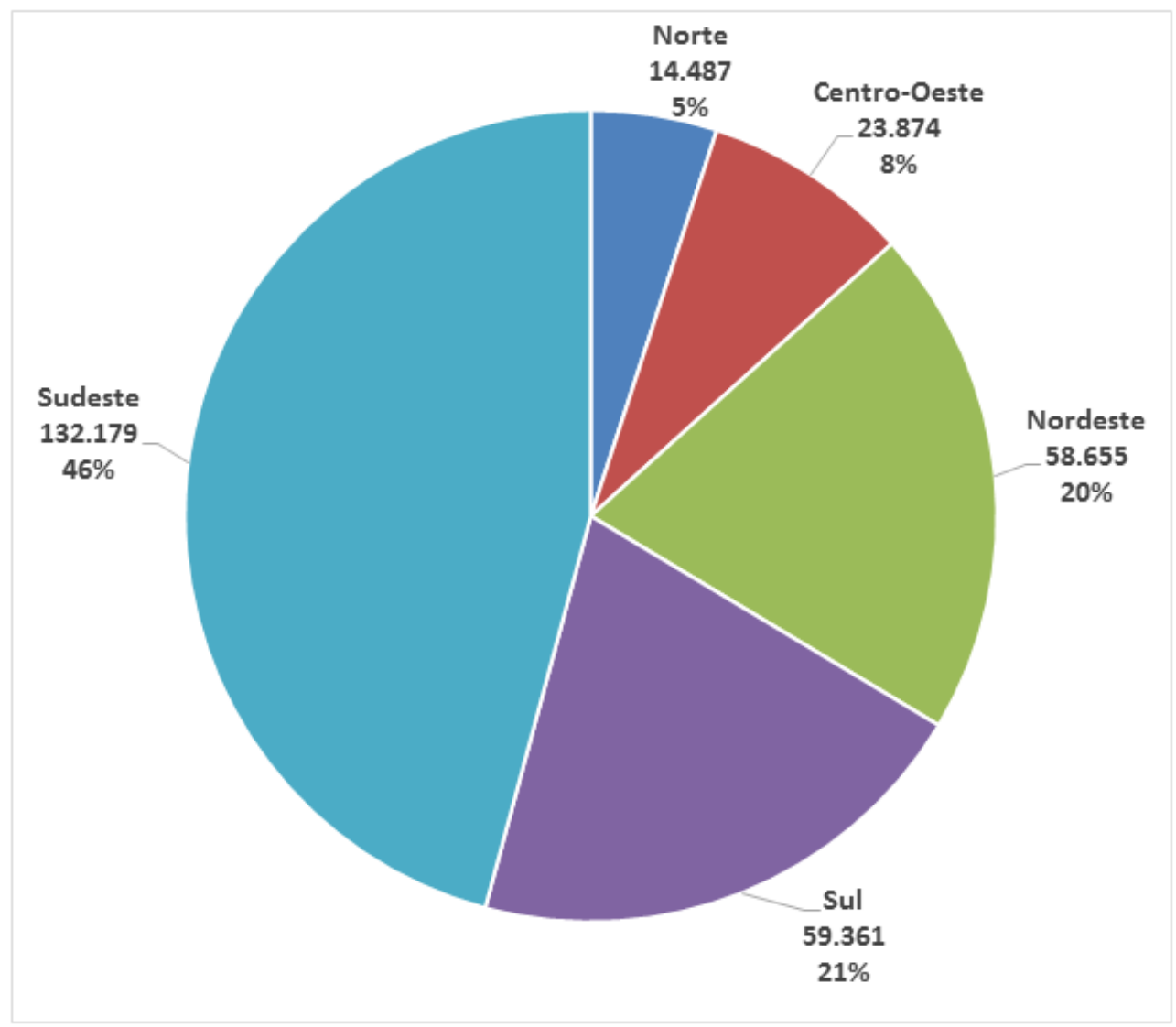

Figura 1 - Quantidade de EAS por região em março de 2016 (Fonte: CNES). 
Em janeiro de 2010, a ANVISA aprovou a resolução RDC/ANVISA n ${ }^{0}$ 02, definindo que todos os EAS devem promover o gerenciamento das tecnologias em saúde, utilizadas na prestação de serviços, desde a aquisição até seu descarte, incluindo o planejamento dos recursos físicos, materiais e humanos. O GTS constitui um instrumento essencial à organização e a estruturação dos estabelecimentos de saúde (ANVISA, 2010).

Segundo esta resolução, entende-se por Gerenciamento de Tecnologias em Saúde: "conjunto de procedimentos de gestão, planejados e implementados a partir de bases científicas e técnicas, normativas e legais, com o objetivo de garantir a rastreabilidade, qualidade, eficácia, efetividade, segurança e em alguns casos o desempenho das tecnologias de saúde utilizadas na prestação de serviços de saúde."

Foram definidos os critérios mínimos para o GTS, sendo estabelecidas as bases para a criação de um plano de gerenciamento para as tecnologias sobre controle e fiscalização sanitárias, abrangidas na RDC/ANVISA $n^{\circ}$ 02/10, em todo o ciclo de vida (aquisição, uso e descarte).

Posteriormente, em novembro de 2011, a ANVISA editou a resolução RDC/ANVISA $n^{\circ} 63$, que descreve os requisitos de boas práticas de funcionamento para os serviços de saúde. Esta nova resolução amplia e estabelece novas diretrizes e fundamentos na qualificação, na humanização da atenção e gestão, na redução e controle de riscos aos usuários e meio ambiente (ANVISA, 2011).

A resolução RDC/ANVISA n ${ }^{\circ} 63$ destaca, no âmbito GTS e processos:

"O serviço de saúde deve realizar o gerenciamento de suas tecnologias de forma a atender as necessidades do serviço mantendo as condições de seleção, aquisição, armazenamento, instalação, funcionamento, distribuição, descarte e rastreabilidade."

Estas resoluções expressam a importância da GTS para os EAS e o quanto é importante a sua adoção para melhoria dos processos internos.

\subsubsection{Plano de Gerenciamento}

O Plano de Gerenciamento deve seguir a legislação sanitária vigente, visando à segurança do paciente, à redução de eventos adversos e a melhoria da qualidade dos serviços prestados. Os EAS devem manter acessível, a todas as pessoas envolvidas, o plano de 
gerenciamento, desde os profissionais do estabelecimento de saúde às autoridades sanitárias (ANVISA, 2010).

Para o sucesso de um Plano de Gerenciamento deve haver envolvimento de todos os membros do EAS, da direção, profissionais de saúde, profissionais de apoio e principalmente do departamento de Engenharia Clínica (EC) (MINISTÉRIO DA SAÚDE, 2012).

É responsabilidade da direção dos EAS (MINISTÉRIO DA SAÚDE, 2012):

1. Assegurar a elaboração e o cumprimento do Plano de Gestão de Equipamentos em conformidade com as metas organizacionais e a legislação, oferecendo condições para que o plano seja compreendido, implementado e mantido em todos os níveis da instituição;

2. Definir o responsável pela gestão de equipamentos e ter estrutura organizacional documentada e estabelecida em seu organograma;

3. Garantir que todas as atribuições e responsabilidades profissionais inerentes à gestão de equipamentos estejam formalmente designadas, descritas, divulgadas e compreendidas por todos;

4. Assegurar que a gestão de equipamentos participe de todas as atividades inerentes à sua área de atuação;

5. Assegurar o cumprimento de programa de educação continuada para os profissionais envolvidos na gestão de equipamentos.

É responsabilidade dos profissionais de saúde (MINISTÉRIO DA SAÚDE, 2012):

1. Assegurar a capacitação dos usuários na operação dos equipamentos;

2. Verificar o cumprimento do Plano de Gestão de Equipamentos em sua área;

3. Notificar a Gestão de Equipamentos sobre todas as ocorrências envolvendo os equipamentos da área;

4. Conservar, higienizar e assegurar a desinfecção dos equipamentos sob sua responsabilidade;

5. Certificar-se de que o equipamento, antes de sua utilização, está com qualificações, calibrações e manutenções conformes (por intermédio de etiquetas ou outro controle existente). 
É responsabilidade do departamento de EC (MINISTÉRIO DA SAÚDE, 2012):

1. Elaborar, implantar, monitorar e avaliar a execução e a efetividade do Plano de Gestão de Equipamentos;

2. Registrar de forma sistemática a execução das atividades de cada etapa do Plano de Gestão de Equipamentos e garantir a rastreabilidade das informações;

3. Apoiar as áreas usuárias na elaboração e aplicação dos Protocolos de Validação de processo;

4. Elaborar um programa de educação permanente para os profissionais envolvidos nas atividades de gestão de equipamentos;

5. Manter atualizado o Plano de Gestão de Equipamentos;

6. Manter disponíveis os resultados da avaliação anual das atividades do Plano de Gestão a todos os profissionais envolvidos.

\subsection{PROCESSO DE GESTÃO DE TECNOLOGIAS EM SAÚDE}

A sistemática do processo de gestão de tecnologias em saúde do EAS deve prever todas as fases do ciclo de vida das tecnologias controladas.

O ciclo de vida pode ser divido em três grupos básicos de processos, que descrevem as atividades que devem ser realizadas em cada etapa do ciclo de vida de um equipamento, conforme pode ser verificado na Tabela 1 (MINISTÉRIO DA SAÚDE, 2012).

Tabela 1 - Ciclo de Vida de Tecnologias em Saúde.

\begin{tabular}{|c|c|}
\hline Processo & Atividade \\
\hline Aquisição & $\begin{array}{ll}\text { - Levantamento da necessidade e } \\
\text { Especificação do equipamento } \\
\text { - Compra } \\
\text { - Recebimento } \\
\text { - Instalação }\end{array}$ \\
\hline Operação & $\begin{array}{l}\text { - Levantamento e identificação do } \\
\text { - } \text { parque tecnológico } \\
\text { - } \text { Manutenção preventiva } \\
\text { - } \text { Calibração } \\
\end{array}$ \\
\hline Descarte & - Retirada de uso e obsolescência \\
\hline
\end{tabular}




\subsubsection{Processo de Aquisição}

Vários passos são necessários antes da aquisição de qualquer tecnologia em saúde. Porém, os levantamentos de informações que permitam a padronização de materiais, medicamentos e equipamentos médicos devem ter destaque importante, pois ao se padronizar esses critérios é assegurada a melhor aplicação dos processos internos préexistentes, a transparência e visibilidade a toda cadeia operacional dos EAS (HERMINI, 2013).

\subsubsection{Processo de Aquisição - Levantamento da necessidade e especificação do equipamento}

O levantamento da necessidade, especificação e os pré-requisitos de compra de qualquer tecnologia em saúde devem fazer parte do termo de referência de aquisição (memorial), que será encaminhado à direção do EAS. Devem fazer parte da comissão, que irá elaborar o levantamento de necessidade e especificação, os profissionais de saúde da área usuária e o departamento de EC, no papel de responsável da Gestão de Equipamentos. Essa interação visa atender e adequar a tecnologia ao interesse de todos (direção, usuário, gestor de tecnologia) (MINISTÉRIO DA SAÚDE, 2012).

\subsubsection{Processo de Aquisição - Compra}

Deve-se buscar no mercado empresas que ofereçam as opções de compras dentro do especificado, as propostas devem ir de encontro ao interesse de todos os envolvidos, como recursos tecnológicos que permitam os profissionais de saúde atenderem aos pacientes com excelência desejada, conciliem custos operacionais e de manutenção dentro do estabelecido pela EC e que estejam dentro da realidade financeira estabelecida pela direção do EAS. As propostas apresentadas deverão ser submetidas à análise de todos os envolvidos, para que dessa forma seja escolhida a proposta que melhor se adeque a realidade (MINISTÉRIO DA SAÚDE, 2012).

\subsubsection{Processo de Aquisição - Recebimento}

A EC, na função de responsável da gestão de equipamentos, deverá acompanhar o processo de recebimento do equipamento, juntamente com a documentação e todos os itens necessários para a instalação. É importante que os documentos fiscais sejam atestados em definitivo, após a verificação da conformidade do equipamento entregue com as especificações de aquisição (MINISTÉRIO DA SAÚDE, 2012). 


\subsubsection{Processo de Aquisição - Instalação}

A instalação dos equipamentos devem seguir rigorosamente as recomendações estabelecidas pelo fabricante e constante na documentação técnica. Após a instalação, a EC deve proceder a aprovação e validação dos equipamentos, estabelecer as rotinas para: treinamento técnico operacional, intervenções técnicas para a manutenção preventiva e calibrações (MINISTÉRIO DA SAÚDE, 2012).

\subsubsection{Processo de Operação - Levantamento e identificação do parque tecnológico}

O conhecimento do parque instalado de tecnologias em saúde, presente em um EAS, é fundamental para que o departamento de EC possa estruturar e estabelecer um Plano de Gerenciamento. Para tanto, faz-se necessário realizar inventário de todos os equipamentos periodicamente, identificando os equipamentos por número de patrimônio ou codificação própria. A identificação deve ser única, permitindo a completa rastreabilidade, gerando dessa forma um prontuário para cada equipamento onde serão registrados todo o histórico do equipamento de intervenções técnicas, condições gerais de funcionamento, avaliações das condições de uso e qualquer outra informação relevante (MINISTÉRIO DA SAÚDE, 2012).

\subsubsection{Processo de Operação - Manutenção preventiva}

Todos os equipamentos presentes em um EAS estão sujeitos à manutenção preventiva, principalmente aqueles que direta ou indiretamente impactam na rotina da instituição, cuja parada ou mau funcionamento venham a comprometer a qualidade, interromper ou reduzir os resultados para limites não toleráveis dos atendimentos aos pacientes (MINISTÉRIO DA SAÚDE, 2002).

É necessária a definição de uma rotina para as intervenções técnicas preventivas, estabelecendo-se os intervalos de tempo entre as intervenções de acordo com as particularidades de cada equipamento. As intervenções técnicas preventivas devem fazer parte da agenda do EAS, constando de um Plano de Manutenção Preventiva, que deverá ser atualizado anualmente (MINISTÉRIO DA SAÚDE, 2002).

Durante a realização do Plano de Manutenção Preventiva devem ser registradas, no histórico de cada equipamento, as atividades realizadas. É importante que o cronograma de manutenção preventiva seja de conhecimento de todos do EAS, para que não haja comprometimento nos atendimentos aos pacientes, de forma que a intervenção técnica 
ocorra conforme o planejado com o menor impacto possível para as instituições (MINISTÉRIO DA SAÚDE, 2002).

\subsubsection{Processo de Operação - Manutenção corretiva}

Caso seja identificado qualquer problema, quebra ou falha, com algum Equipamento Médico-Hospitalar (EMH) os usuários são responsáveis pela notificação e registro de solicitação de manutenção corretiva junto à EC (CALIL e TEIXEIRA, 1998).

Após a intervenção técnica para a correção do problema apresentado e a realização dos testes de validação, com a comprovação da eficácia do serviço, a EC deverá avaliar a necessidade de nova calibração do equipamento, tendo por base a documentação técnica do fabricante e a legislação em vigor (CALIL e TEIXEIRA, 1998).

Ao término da manutenção corretiva devem ser registradas, no histórico de cada equipamento, as atividades realizadas. É importante que ao final o usuário ateste o recebimento do equipamento em condições perfeitas para o uso (CALIL e TEIXEIRA, 1998).

\subsubsection{Processo de Operação - Calibração}

Os equipamentos sujeitos à calibração são aqueles cujos parâmetros físicos de funcionamento interfiram diretamente na qualidade do produto ou serviço (MINISTÉRIO DA SAÚDE, 2012).

Para os equipamentos que requerem calibração, torna-se necessário o estabelecimento de um Plano de Calibração, no qual de acordo com a necessidade e particularidade de cada equipamento, seja estabelecido um cronograma e especificados critérios de calibração, de acordo com valores e critérios estabelecidos na documentação fornecida pelo fabricante. As calibrações devem ser realizadas por entidade qualificadas e registradas, de forma a garantir que os equipamentos estejam operando de acordo com a especificação e que não ofereçam quaisquer riscos aos pacientes e/ou seus operadores. Os processos de calibração devem ser documentados e anexados ao histórico de cada equipamento (MINISTÉRIO DA SAÚDE, 2012).

\subsubsection{Processo de Descarte - Retirada de uso e obsolescência}

É importante e necessário o descarte adequado dos equipamentos médico-hospitalares, respeitando a legislação conforme a Política Nacional de Resíduos Sólidos (Lei $\mathrm{n}^{\mathrm{o}}$ 12305/10) e o Gerenciamento de Resíduos de Saúde (Resolução ANVISA RDC n ${ }^{\circ}$ 
306/2004), observando os critérios de logística reversa para estes produtos. Já existe um consenso da indústria que os fabricantes são corresponsáveis nos descarte do e-lixo (lixo proveniente de equipamentos eletro-eletrônicos), devendo estes estabelecer uma infraestrutura para coleta do e-lixo de destinação adequada para os resíduos.

São condições para a retirada de uso:

○ O equipamento não atende à demanda;

○ Há perda de confiabilidade referente ao equipamento;

○ Mudança dos parâmetros do processo;

- Mudança das normas;

○ Custo / benefício para reparo;

- Riscos / falhas de operação;

○ O equipamento não apresenta condições de uso em nenhum outro processo.

Cabe ao departamento de EC, monitorar os parâmetros que estabelecem que um equipamento encontra-se na situação de descarte, devendo informar as partes envolvidas a necessidade da retirada de uso e quando for caso providenciar a aquisição de nova tecnologia ou equipamento que substituirá àquele que será retirado de uso.

\subsection{IDENTIFICAÇÃO POR RÁDIO FREQUÊNCIA}

A identificação por rádio frequência ou RFID, permite a identificação de itens utilizandose de ondas de rádio frequência e dispositivos eletrônicos de leitura (GLOVER e BHATT, 2007).

O RFID não é uma tecnologia recente, os primeiros estudos datam da Segunda Guerra Mundial e foram liderados por Watson-Walt para o governo britânico, para uso na identificação de aeronaves. Porém, sua adoção em maior escala tem-se dado nos últimos anos, principalmente com redução dos custos dos dispositivos de hardware e software necessários para viabilizar a utilização dessa tecnologia (SWEENEY, 2007).

A tecnologia RFID é uma de tecnologia de auto-identificação sem fio. A tecnologia auto-identificação possibilita a identificação de pessoas ou objetos automaticamente através de um código. Como exemplos de tecnologias de auto-identificação é possível citar: o código de barras, o fingerprint, o leitor de retina ou de voz, entre outros. Cada uma dessas tecnologias utilizam características que carregam o código de identificação único: o código de barras utiliza um código binário para identificar itens, o fingerprint utiliza a 
impressão digital para identificar pessoas, o leitor de retina detecta o desenho da retina e o compara com o banco de dados existente e assim por diante. No caso da RFID, utiliza-se ondas eletromagnéticas de rádio frequência para ler o código de identificação dos itens (pessoas, animais, materiais, equipamentos, perecíveis, entre outros) gravado em um microchip (GLOVER e BHATT, 2007), conforme apresentado na Figura 2.

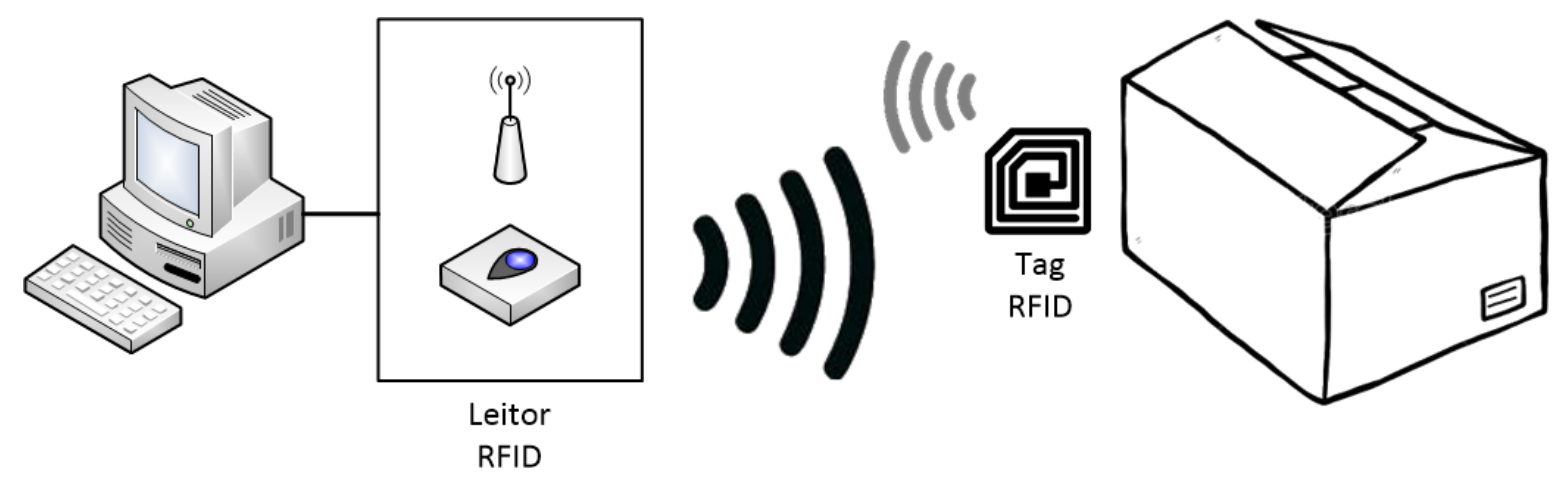

Figura 2 - Esquema de um sistema RFID.

\subsubsection{Faixas de frequência das RFID}

A tecnologia RFID utiliza ondas de rádio frequência ente $30 \mathrm{kHz}$ e $5,8 \mathrm{GHz}$. Com a evolução dos padrões foram estabelecidas faixas mais específicas para a utilização do RFID, são mais comumente encontradas as faixas de 125/134 kHz, 13,56 MHz, 860-960 MHz e 2,4-2,45 GHz (GLOVER e BHATT, 2007).

As frequências estão sujeitas à regulamentação dos governos, para que dessa forma não interfiram em outras aplicações estabelecidas. A definição da frequência de trabalho tem influência direta no desempenho da aplicação, impactando na precisão, alcance e velocidade de leitura, susceptibilidade a interferência, etc. Frequências mais baixas, por exemplo, são mais capazes de viajar sobre a água, enquanto frequências mais altas podem carregar mais informações (GLOVER e BHATT, 2007).

Na prática, a banda de frequência que pode ser utilizada pela tecnologia é limitada ao grupo Industrial Scientific Medical (ISM) e baseado nessas regulamentações e nas características listadas anteriormente, as ondas de rádio utilizadas pela tecnologia RFID são divididas em cinco faixas de frequência: baixa frequência ou low frequency (LF), alta frequência ou high frequency (HF), frequência muito alta ou very high frequency (VHF), 
ultra alta frequência ou ultra high frequency (UHF) e micro-onda ou microwave frequeny (LAHIRI, 2006).

$\mathrm{Na}$ Tabela 2 são apresentadas as principais características e aplicações das faixas de frequências mais populares utilizadas na implementação de sistemas RFID. A escolha da frequência de operação está relacionada com a finalidade da aplicação, de forma a alcançar os melhores resultados em determinado contexto (LAHIRI, 2006).

Tabela 2 - Características e aplicações das faixas de frequência populares em RFID (GLOVER e BHATT, 2007).

\begin{tabular}{|c|c|c|}
\hline Frequência & Principais Características & Aplicações \\
\hline $\begin{array}{l}\text { abaixo de } \\
135 \mathrm{KHz}\end{array}$ & $\begin{array}{l}\text { - Amplamente utilizada desde década de } 80 \\
\text { - Funciona bem com líquido e metal } \\
\text { - Menor velocidade de transferência de dados } \\
\text { - Alcance na faixa de centímetros }\end{array}$ & $\begin{array}{l}\text { - Identificação de animais } \\
\text { - Automação industrial } \\
\text { - Controle de acesso }\end{array}$ \\
\hline $13,56 \mathrm{MHz}$ & $\begin{array}{l}\text { - Amplamente usada desde década de } 90 \\
\text { - Padrões mundiais populares } \\
\text { - Alcance maior que a de LF (mais de } 1 \\
\text { metro) } \\
\text { - Custo das tags menor que as de LF } \\
\text { - Desempenho limitado na presença de } \\
\text { metais }\end{array}$ & $\begin{array}{l}\text { - Cartões de crédito e } \\
\text { fidelidade (smart cards) } \\
\text { - Controle de acesso } \\
\text { - Combate à falsificação } \\
\text { - Várias aplicações de } \\
\text { rastreamento de itens } \\
\text { como livros, bagagem, } \\
\text { vestuário, etc } \\
\text { - Prateleiras inteligentes } \\
\text { - Identificação e } \\
\text { monitoração de pessoas }\end{array}$ \\
\hline $\begin{array}{c}433 \mathrm{MHz} \text { e } \\
860-930 \\
\mathrm{MHz}\end{array}$ & $\begin{array}{l}\text { - Em uso desde final da década de } 90 \\
\text { - Alcance maior que a de HF (mais de } 3 \\
\text { metros) } \\
\text { - Alcance longo para sistemas ativos em } 433 \\
\text { MHz (até centenas de metros) } \\
\text { - Ganhando força devido às exigências de } \\
\text { cadeias de suprimentos de varejistas globais } \\
\text { - Potencial de oferecer os tags mais baratos } \\
\text { - Problemas de incompatibilidade entre } \\
\text { regulamentações locais } \\
\text { - Suscetibilidade de interferência de líquido e } \\
\text { metal }\end{array}$ & $\begin{array}{l}\text { - Cadeia de suprimentos e } \\
\text { logística: } \\
\text { ○ Controle de estoque } \\
\text { o Gerenciamento de } \\
\text { depósitos } \\
\text { o Rastreamento de bens }\end{array}$ \\
\hline $\begin{array}{c}2,45 \text { e } 5,8 \\
\mathrm{GHz}\end{array}$ & $\begin{array}{l}\text { - Em uso por várias décadas } \\
\text { - Transferência de dados rápida } \\
\text { - Comum nos modos ativo e passivo } \\
\text { - Faixa de alcance similar a UHF } \\
\text { - Pior desempenho com líquido e metal }\end{array}$ & $\begin{array}{l}\text { - Controle de acesso } \\
\text { - Coleta eletrônica de } \\
\text { pedágio } \\
\text { - Automação industrial }\end{array}$ \\
\hline
\end{tabular}




\subsubsection{Etiquetas RFID (Tags)}

Uma etiqueta RFID, comumente chamada de etiqueta eletrônica ou tag, é um dispositivo que pode armazenar e transmitir dados para uma leitora sem a necessidade de contato, usando ondas de rádio (LAHIRI, 2006). Usualmente, a tag também é chamada de transponder, derivado dos termos em inglês transmitter e responder (transmissor e respondedor) (MANISH e SHAHRAM, 2005). O propósito de uma tag de RFID é vincular a um objeto um código que permite acesso aos dados pertinentes a ele (LAHIRI, 2006).

De modo geral uma tag RFID é composta por um microchip conectado a uma pequena antena. Tipicamente as tags são montadas sobre um substrato de plástico ou papel, neste formato bruto são chamadas de inlay ou inlet, posteriormente podem ser transformados em etiquetas, cartões ou outros formatos que melhor se adaptem ao tipo de aplicação final, conforme Figura 3 (LAHIRI, 2006).

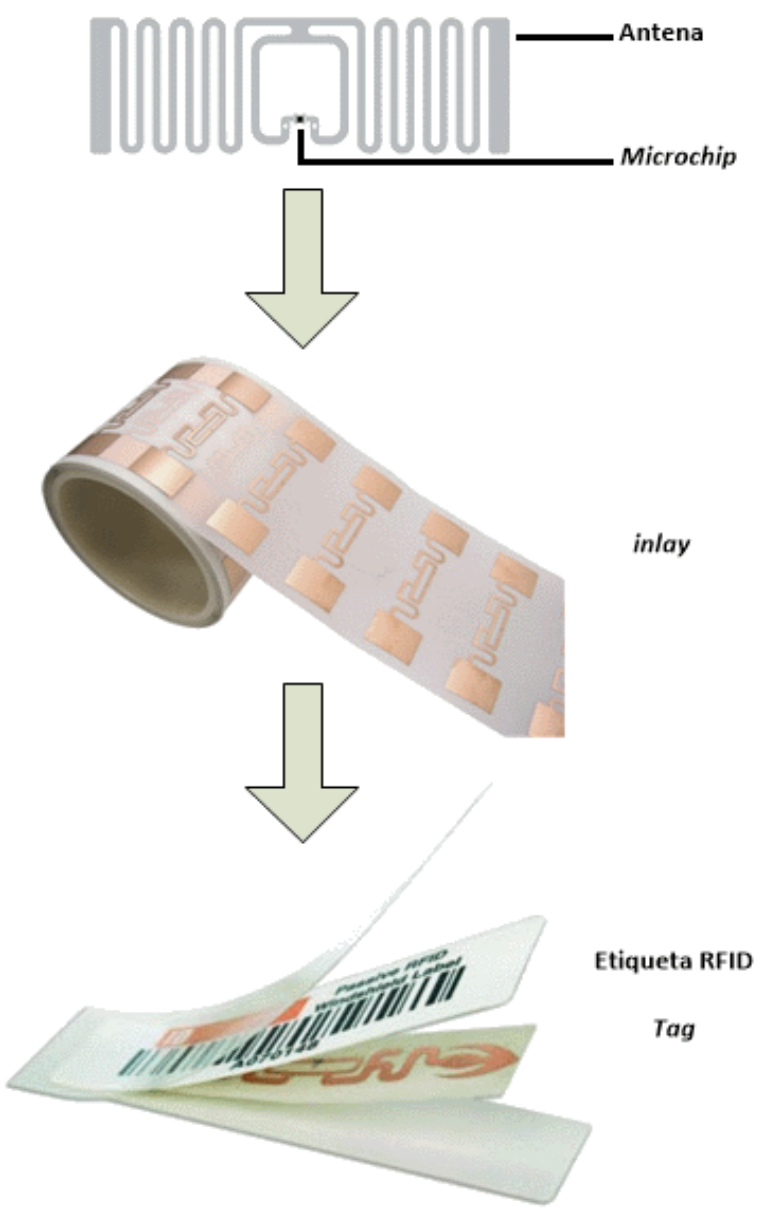

Figura 3 - Componentes de uma tag RFID. Adaptado de LAHIRI, 2006. 


\subsubsection{Tipos de Tags RFID}

As tags podem ser classificadas com base em suas características, uma forma é a classificação das tags é baseado no tipo de alimentação utilizado em seus circuitos, que pode ser obtida a partir do sinal recebido das antenas da leitora ou pode fazer uso de uma bateria interna. Dependendo da fonte de energia, as tags podem ser classificadas como passivas, ativas e semi-ativas (ou semi-passivas) (LAHIRI, 2006).

As tags passivas não possuem uma fonte de alimentação própria e obtém energia do campo eletromagnético criado pelo sinal propagado em torno das antenas da leitora. A tag utiliza esta energia para alimentar todo o seu circuito e também para enviar o sinal de resposta à leitora. Isso limita o seu alcance a pouco mais de três metros. Como não usa bateria e sua constituição é basicamente o microchip e a antena, este tipo de tag é a opção mais barata para rastreamento de produtos na cadeia de suprimentos, um exemplo de tag passiva é apresentado na Figura 4 (LAHIRI, 2006).

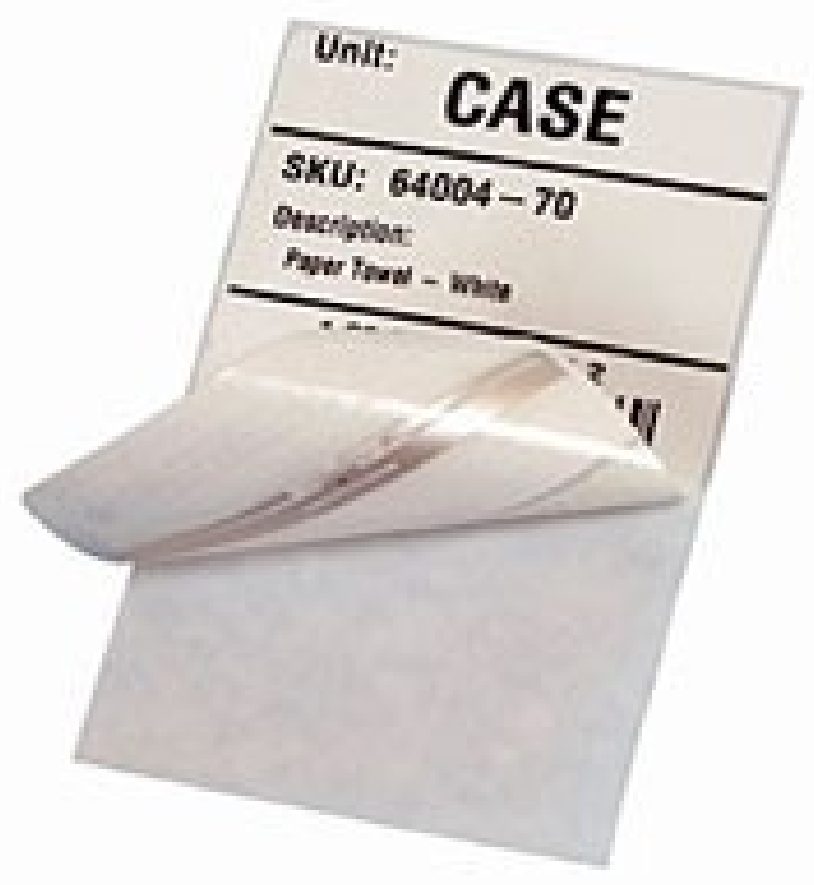

Figura 4 - Tag RFID Passiva. 
As tags ativas têm uma fonte de alimentação interna, conforme observado na Figura 5, que é usada para ativar os circuitos do microchip e para enviar o sinal de resposta à leitora. Esse tipo de tag pode ser lido a grandes distâncias e consegue responder a sinais bastante atenuados. Algumas tags ativas podem atingir um alcance de centenas de metros (LAHIRI, 2006).

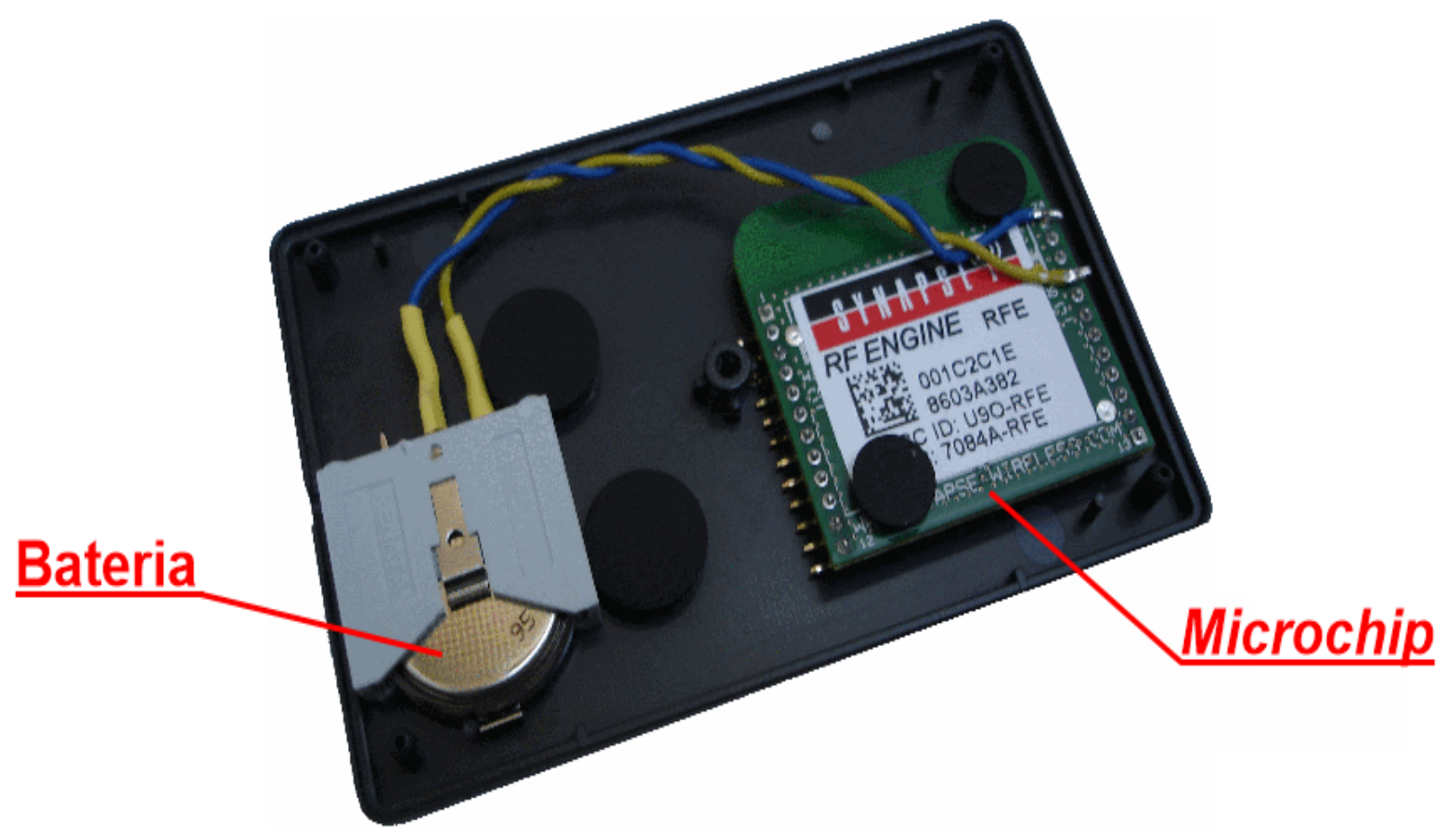

Figura 5 - Tag RFID Ativa.

As tags as semi-passivas ou semi-ativas também possuem uma bateria interna para sua alimentação, assim como as ativas. Entretanto, assim como as passivas, elas precisam da presença de um leitor para envio das informações, pois não possuem um modulador e não são, portanto, capazes de enviar por si só um sinal de radiofrequência (LAHIRI, 2006).

\subsubsection{Leitores RFID}

Leitores RFID permitem a leitura dos códigos armazenados nas tags RFID e fazem a interface com os sistemas de gestão. Normalmente os leitores RFID são constituídos de componentes físicos (hardware) e componentes lógicos (software) (LAHIRI, 2006) (GLOVER e BHATT, 2007). 
Os leitores RFID emitem sinais que procuram uma etiqueta. Quando uma etiqueta estiver dentro do raio de ação será ativada pelo sinal do leitor, que irá proporcionar a energia para a etiqueta responder com os dados registrados nela, na Figura 6 são apresentados alguns modelos de leitores RFID (LAHIRI, 2006) (GLOVER e BHATT, 2007).
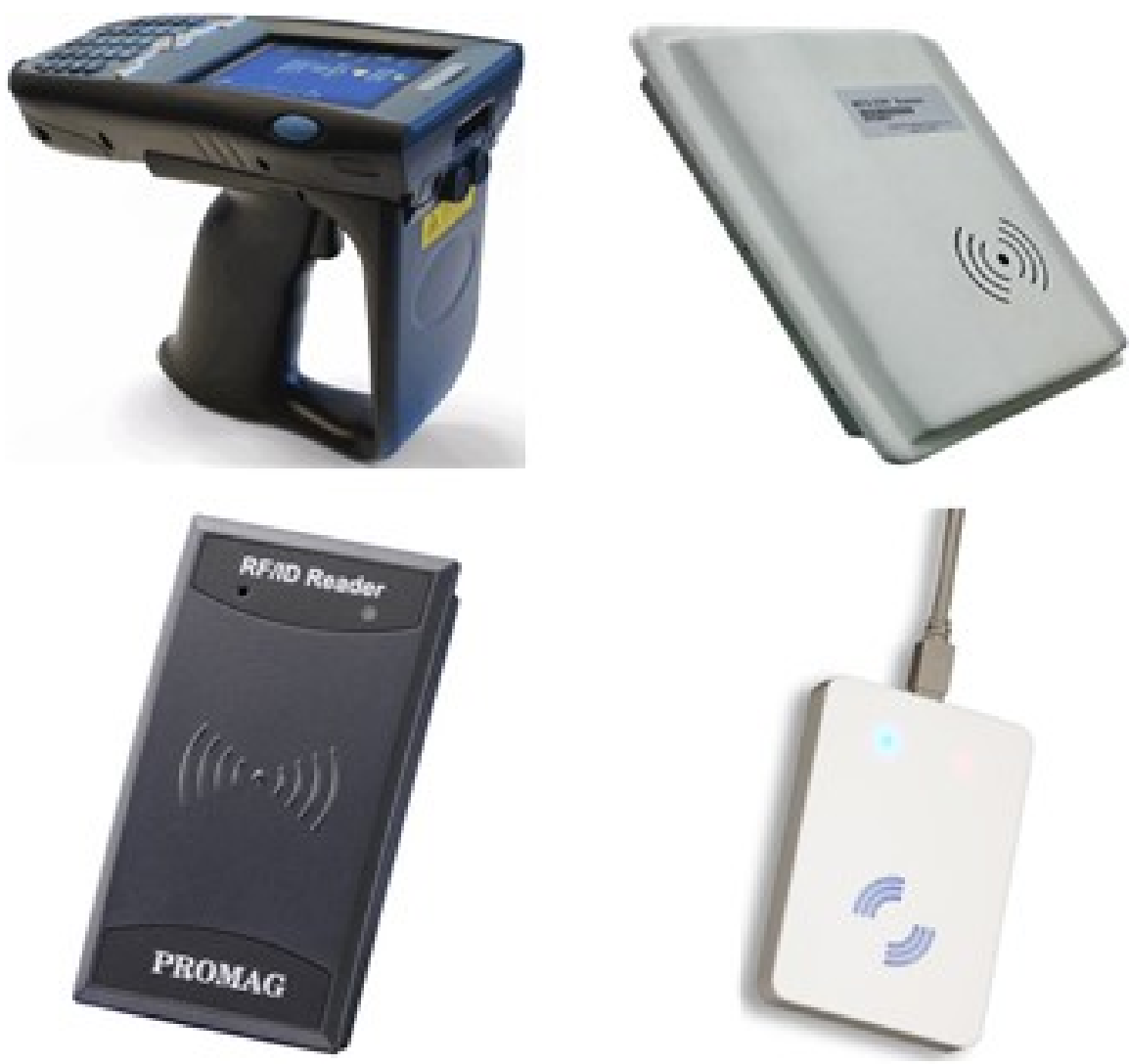

Figura 6 - Leitores RFID para tags passivas.

Os leitores são subdivididos em dois tipos: os de leitura e os de leitura/escrita. Os de leitura são utilizados normalmente com as etiquetas passivas e somente leem os dados presentes nas etiquetas. Os de leitura/escrita são utilizados com as etiquetas ativas e passivas, podendo ler e escrever dados dependendo do tipo de etiqueta (LAHIRI, 2006). 


\subsection{TECNOLOGIAS E FERRAMENTAS COMPUTACIONAIS}

Para o desenvolvimento do sistema foram adotadas algumas tecnologias e ferramentas computacionais, estes recursos visam facilitar e acelerar o processo de desenvolvimento a partir de padrões consolidados.

\subsubsection{HTML}

O Hypertext Markup Language (HTML) é uma linguagem para estruturação e apresentação de conteúdo para a World Wide Web e é a tecnologia chave da internet moderna. Desenvolvido originalmente por Tim Berners-Lee o HTML ganhou popularidade quando o Mosaic - browser desenvolvido por Marc Andreessen na década de 1990 ganhou força. A partir daí, desenvolvedores e fabricantes de browsers utilizaram o HTML como base, compartilhando as mesmas convenções (FERREIRA e EIS, 2014).

A linguagem HTML é utilizada para criação de websites e desde o começo foi criada para ser uma linguagem independente de plataformas, browsers e outros meios de acesso. Interoperabilidade significa menos custo. É possível criar apenas um código HTML e este código pode ser lido por diversos meios, ao invés de versões diferentes para diversos dispositivos. Dessa forma, evitou-se que a $\mathrm{Web}$ fosse desenvolvida em uma base proprietária, com formatos incompatíveis e limitada. Esta linguagem foi criada para ser de fácil entendimento por seres humanos e também por máquinas, sendo baseada no conceito de marcações ou tags. As tags HTML são utilizadas para descrever os elementos que compõem uma página (FERREIRA e EIS, 2014).

As tags são usadas sempre aos pares, uma para abertura e outra para fechamento. Um documento HTML é composto por vários pares de tags, sendo que é possível aninhar tags dentro de outras tags, de forma a estruturar os dados que serão apresentados em uma página (FERREIRA e EIS, 2014). Na Figura 7 é apresentado um exemplo de como as tags são utilizadas.

〈h1>Aqui vai o texto do título</h1〉

Figura 7 - Exemplo de marcação HTML. 
O HTML encontra-se atualmente na versão 5, onde ao contrário das versões anteriores, fornece ferramentas para Cascading Style Sheets (CSS) e o Javascript fazerem seu trabalho da melhor maneira possível. O HTML5 permite por meio de suas Application Programming Interfaces (API) a manipulação das características destes elementos, de forma que o website ou a aplicação continue leve e funcional segundo European Computer Manufacturers Association (ECMA).

\subsubsection{CSS}

CSS permite a definição de estilos para formatação da apresentação dos elementos que compõem as páginas $W e b$, é possível definir efeitos de transição, imagem e outros aspectos. Estes recursos permitem a criação de páginas com layouts avançados, que formam a base da Web 2.0 (W3C ESCRITÓRIO BRASIL, 2014).

O uso do CSS em conjunto com o HTML5 permite a manipulação visual dos elementos da página de maneira altamente elaborada, aperfeiçoando a criação de páginas responsivas (W3C ESCRITÓRIO BRASIL, 2014). Na Figura 8 é apresentado um exemplo de um bloco de definições CSS para elementos HTML.

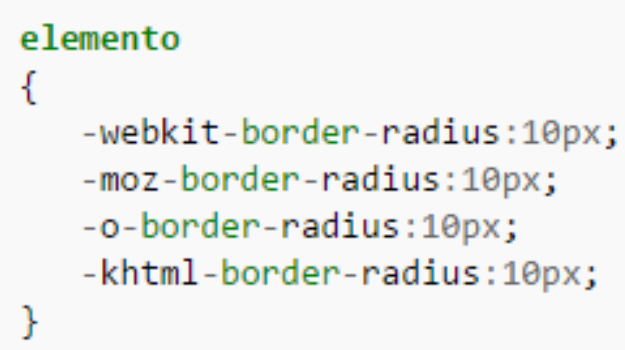

Figura 8 - Exemplo de definição de estilo CSS.

\subsubsection{Javascript}

A linguagem Javascript foi criada na Netscape por Brendan Eich em 1996, sendo uma linguagem de script bastante flexível, de tipos dinâmicos, com conceitos de linguagem procedural (similar à linguagem de programação $\mathrm{C}$ ), funcional (similar à linguagem de programação Scheme) e orientada a objetos (similar às linguagens de programação Self e Java). A linguagem é interpretada pelo navegador Web e executada do lado do cliente. Seu código pode ser embutido no código HTML ou em arquivos separados. O script gerado é 
capaz de interagir com os elementos e tags definidos no HTML, sendo por isso considerada uma ferramenta poderosa no desenvolvimento $\mathrm{Web}$, principalmente com o avanço da tecnologia Asynchronous JavaScript and XML (AJAX) (FLANAGAN, 2013).

Atualmente todos os navegadores modernos implementam o Javascript em seus motores de renderização, a linguagem se encontra na versão 3 é padronizada pela ECMA.

\subsubsection{Single Page Application (SPA)}

Uma aplicação Single Page Application (SPA) segue o princípio que a aplicação estará quase toda no lado cliente, sendo que quando o usuário acessa o site pela primeira vez toda a aplicação e seus templates são carregados e armazenados no lado cliente, diferente da forma tradicional, onde o usuário visita várias páginas diferentes (MONTEIRO, 2014).

Com as aplicações SPA sendo carregadas totalmente no primeiro acesso ao site, os usuários tem uma experiência de utilização mais próximas as aplicações nativas, com transições de telas mais rápidas e naturais (MONTEIRO, 2014).

Entre as vantagens de uma aplicação SPA destacam-se:

- Melhor balanceamento da responsabilidade da execução entre cliente e servidor;

- Melhor experiência do usuário (UX), interfaces com usabilidade moderna;

- Menor consumo de banda, pois as cargas de dados são feitas por demanda e por AJAX

O diferencial de uma aplicação SPA é o código Javascript executado no cliente. Toda a aplicação pode ser construída simplesmente manipulando o Document Object Model (DOM) de forma nativa, ou com o uso de bibliotecas e frameworks Javascript que auxiliam na construção da aplicação. Estas bibliotecas e frameworks fornecem recursos para manipulação dinâmica do DOM, definição de templates de tela, chamadas assíncronas ao servidor, organização do código Javascript, etc. Diversas bibliotecas Javascript têm sido criadas para facilitar o desenvolvimento com SPA, alguns exemplos são: BACKBONE, EMBER, ANGULARJS e KNOCKOUT (MONTEIRO, 2014).

Na Figura 9 é apresenta a visão geral da estrutura de uma aplicação SPA. 


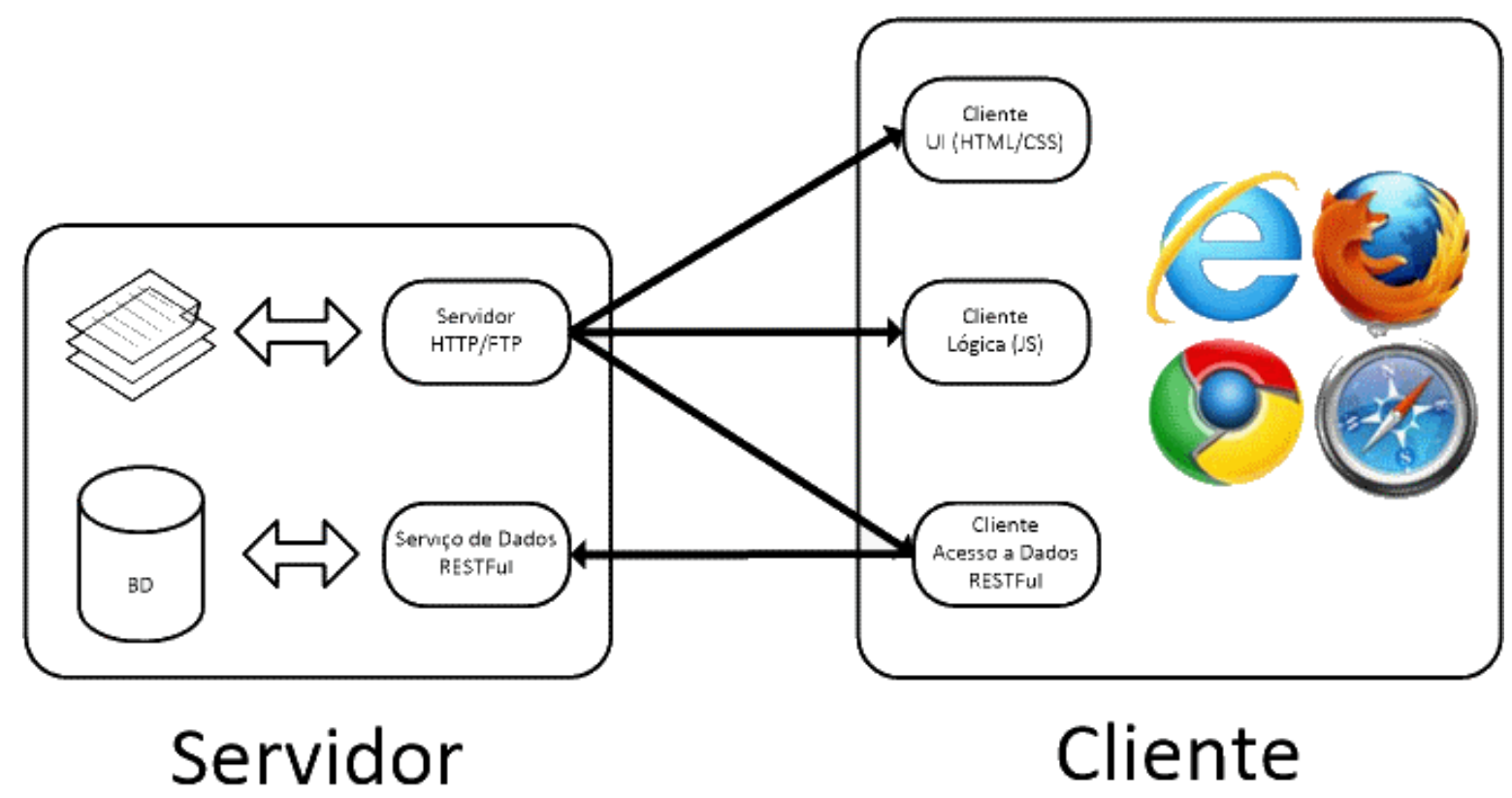

Figura 9 - Esquema de uma aplicação SPA. Adaptado de MONTEIRO, 2014.

\subsubsection{Servidor de Banco de Dados PostgreSQL}

Um Sistema de Gerenciamento de Banco de Dados (SGBD) é um conjunto ferramentas de software responsáveis pelo gerenciamento de base de dados. O PostgreSQL é um SGBD objeto-relacional de código aberto, com mais de quinze anos de desenvolvimento ativo e uma arquitetura de forte reputação pela sua confiabilidade, integridade de dados e conformidade com os padrões de mercado. Este SGBD tem sido utilizado em inúmeros projetos na indústria farmacêutica, instituições de saúde, mercado financeiro, instituições de ensinos, empresas de telecomunicações e em várias outras áreas. Entre as empresas e instituições que utilizam o PostgreSQL estão: Greenpeace, U.S. State Department, United Nations Children's Fund, Trust-Commerce, Berkman Center for Internet \& Society at Harvard University, University of California - Berkeley e BASF - Agricultural Product Division. O PostgreSQL possui versão para todos os principais sistemas operacionais, incluindo GNU/Linux, Unix (AIX, BSD, HP-UX, SGI IRIX, macOS X, Solaris, Tru64) e Microsoft Windows. Implementa os conceitos de atomicidade, consistência, integridade e durabilidade (ACID), tem suporte completo a chaves estrangeiras, junções, visões, gatilhos e procedimentos armazenados. Inclui a maior parte dos tipos de dados do padrão ISO SQL:1999, incluindo INTEGER, NUMERIC, BOOLEAN, CHAR, VARCHAR, DATE, INTERVAL, e TIMESTAMP. Suporta o armazenamento de objetos binários, incluindo 
figuras, sons ou vídeos. Possui uma vasta documentação e disponibiliza interfaces nativas de programação para as linguagens C/C++, Java, .Net, Perl, Python, Ruby, Tcl, ODBC, entre outras (POSTGRESQL, 2016).

Como um banco de dados de nível corporativo, o PostgreSQL possui funcionalidades sofisticadas como o controle de concorrência de múltiplos níveis, recuperação em um ponto no tempo, tablespaces, replicação assíncrona, transações agrupadas (savepoints), cópias de segurança a quente (online/hot backup), um sofisticado planejador de consultas (otimizador) e registrador de transações sequencial para tolerância a falhas. Oferece suporte aos conjuntos de caracteres internacionais, codificação de caracteres multibyte, Unicode e sua ordenação por localização, formatação e sensibilidade entre letras maiúsculas e minúsculas. É altamente escalável, tanto na quantidade enorme de dados que pode gerenciar, quanto no número de usuários concorrentes que pode suportar (POSTGRESQL, 2016) (DAR, 2015).

Um aspecto decisivo na escolha do PostgreSQL foi total conformidade com os padrões ANSI-SQL 92/99, pois permite a migração da aplicação sem muito esforço para qualquer outro SGBD que também adote este padrão.

\subsubsection{Servidor de aplicativo Node.js}

Como servidor de aplicação Web foi adotado o Node.js. O Node.js é uma plataforma construída sobre o motor JavaScript do Google Chrome, permite facilmente construir aplicações server-side baseadas em rede rápidas e escaláveis. Node.js usa um modelo de I/O direcionada a evento não bloqueante que o torna leve e eficiente, ideal para aplicações em tempo real com troca intensa de dados através de dispositivos distribuídos (NODEJS, 2016).

O Node.js foi criado por Ryan Dahl e o projeto foi apresentado ao mundo em 2009 na JSConf 2009 Européia. Este projeto era uma plataforma que combinava a máquina virtual JavaScript V8 da Google e um laço de eventos (NODEJS, 2016).

Node.js é considerado uma solução mais simples em relação ao servidores de aplicação Web tradicionais, como Apache e Microsoft IIS. As principais vantagens do Node.js são: leveza (não requer muitos recursos do servidor), aceita uma quantidade grande 
de conexões, altamente escalável, relativamente fácil de programar e com uma biblioteca vasta de frameworks, o que facilita o desenvolvimento (NODEJS, 2016).

A opção pelo Node.js como servidor de aplicação foi a possibilidade de utilização de Javascript para desenvolvimento do cliente e do servidor, padronizando a escrita de código e permitindo que boa parte dele seja compartilhada entre os dois lados da aplicação. $O$ reaproveitamento de código é uma das grandes vantagens apontadas pela Engenharia de Software, pois permite ganhos com: aumento da produtividade, otimização de recursos, aumento da qualidade, padronização na escrita do código, acelera o desenvolvimento, reduz o tempo de desenvolvimento e manutenção, entre outros (PRESSMAN, 2011).

\subsubsection{Arduino}

O Arduino é uma plataforma de prototipagem eletrônica de hardware livre, projetada com um microcontrolador Atmel AVR com suporte de entrada/saída embutidos e pode ser programada a partir da linguagem $\mathrm{C} / \mathrm{C}++$. O objetivo desta plataforma é criar ferramentas que são acessíveis, com baixo custo, flexíveis e fáceis de usar (MONK, 2014).

A plataforma Arduino foi utilizada como base para o projeto do leitor de RFID. Sua escolha se deu em função do seu baixo custo e pelo elevado número de módulos auxiliares disponíveis. 


\section{METODOLOGIA}

O desenvolvimento do sistema foi dividido nas etapas de planejamento, projeto e construção. Em cada etapa foram utilizadas as técnicas Engenharia de Software, visando alcançar os melhores resultados na construção do sistema.

\subsection{PLANEJAMENTO}

$\mathrm{Na}$ etapa de planejamento foram levantados os requisitos do sistema, com base na legislação e nas necessidades apontadas por alguns EAS, para definir quais funcionalidades seriam desenvolvidas. A etapa de planejamento foi subdividida em:

\subsubsection{Levantamento de Requisitos}

No Levantamento de Requisitos foram identificados os principais pontos na gestão de EMH estabelecidos pelo MS, a partir das resoluções da ANVISA. Outros pontos levantados nesta etapa foram a dificuldades apontadas pelos EAS na adoção da GTS.

\subsubsection{Análise dos Requisitos}

Com base no Levantamento de Requisitos, foram estabelecidos os aspectos mais importantes em um sistema de GTS conciliados com as realidades dos EAS, desta forma chegou-se ao um conjunto de funcionalidades que descrevem o escopo do sistema. Este escopo deve atender a legislação e ao mesmo tempo não ser uma barreira na adoção do sistema pelos EAS.

\subsection{PROJETO}

Definido o escopo do sistema, foi criado um projeto atendê-lo. Na etapa de projeto foram definidos: a arquitetura do sistema, modelagem, a linguagem de programação utilizada, o SGDB para armazenamento das informações, os padrões de interface gráfica, os diagramas de estruturas do sistema, critérios de segurança, entre outros.

Uma das primícias adotada no projeto foi o desenvolvido com base em tecnologias de código aberto, tendo como requisitos essenciais: a portabilidade (permitindo a 
instalação do servidor em sistemas operacionais Microsoft Windows, Linux ou macOS), segurança e alta performance.

\subsection{IMPLEMENTAÇÃO}

$\mathrm{Na}$ etapa de implementação realizou-se a construção efetiva do sistema, seguindo as definições estabelecidas no projeto. Foi modelado e construído o banco de dados, criadas às classes dos objetos na linguagem de programação adotada, desenvolvidos os serviços de requisições do servidor, construída a interface de usuário para navegadores $W e b$, entre outras.

O processo de desenvolvimento é uma atividade complexa, sendo que todas as etapas passam por revisões constantes, para garantir que o sistema final esteja de acordo com o projeto e atendam as necessidades do EAS. 


\section{RESULTADOS}

A motivação deste trabalho foi desenvolver um sistema que permitisse a gestão dos EMH, que pudesse ser utilizado pelos profissionais de EC dos mais diversos tipos de EAS, de pequenos até os de grande porte. Um dos objetivos do projeto é que o sistema esteja disponível via internet, sem a necessidade da implantação de qualquer infraestrutura auxiliar, que mantenha a segurança e integridade dos dados e seja de fácil operação, além de utilizar a tecnologia RFID como facilitador do processo de gestão.

\subsection{ESTRUTURA DE DESENVOLVIMENTO}

O sistema é composto basicamente em duas partes: cliente Web, com a interface do usuário, e o servidor que recebe todas as requisições do serviço e armazena os dados.

\subsubsection{Arquitetura de Desenvolvimento do Sistema}

A arquitetura adotada no desenvolvimento permite que o sistema seja disponibilizado a partir de um servidor $W e b$, ficando acessível para qualquer terminal conectado à internet, conforme apresentado na Figura 10. A interface é totalmente responsiva e se adapta a qualquer tipo de terminal, oferecendo a mesma experiência quando se opera o sistema a partir de computadores desktop, tablets ou smartphones.
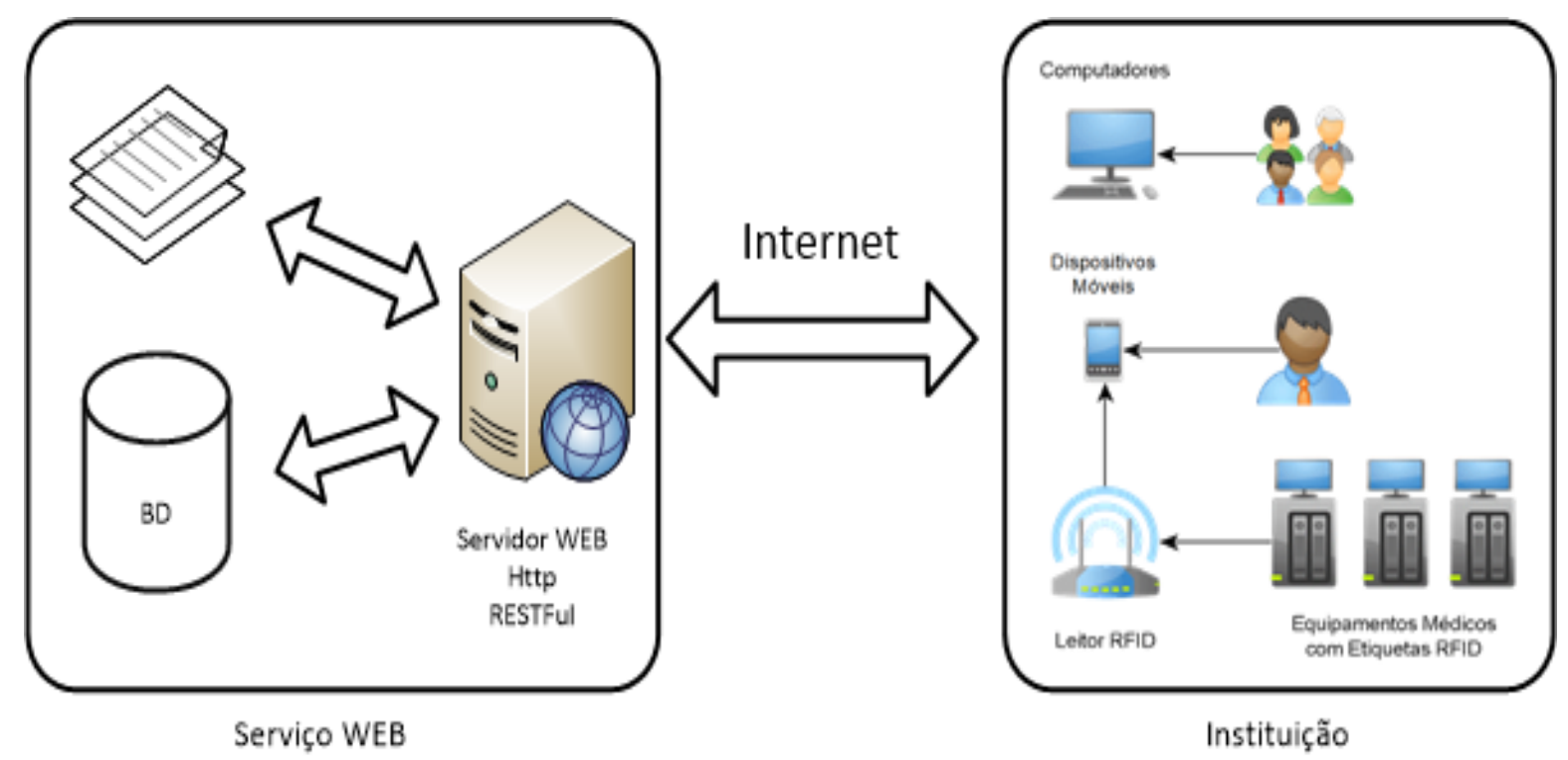

Figura 10 - Estrutura geral do sistema. 
Para o desenvolvimento do sistema foram levantados os requisitos com base com o especificado nas normas da ANVISA e nas boas práticas de gestão dos EMH. Durante o levantamento de dados foram identificados quatro grupos funcionais de informações, que de forma geral, descrevem a organização dos dados a serem manipulados durante o processo de gestão dos EMH nos EAS.

Tabela 3 - Grupos funcionais de dados que compõem o sistema.

\begin{tabular}{l|c}
\hline Grupo & Funcionalidade \\
\hline Grupo 01 - Controle de Acesso & Instituição e Usuário. \\
\hline Grupo 02 - Estrutura das instituições & Unidade, Setor, Sala e Centro de Custo. \\
\hline $\begin{array}{l}\text { Grupo 03 - Gerenciamento dos } \\
\text { Equipamentos }\end{array}$ & $\begin{array}{c}\text { Equipamento, Forma de Aquisição, Tipo de } \\
\text { Manutenção, Ordem de Serviço. }\end{array}$ \\
\hline $\begin{array}{l}\text { Grupo 04 - Fabricantes, Modelos e } \\
\text { Prestadores }\end{array}$ & $\begin{array}{r}\text { Fabricante, Modelo, Princípio de funcionamento } \\
\text { e Prestadores de Serviço. }\end{array}$ \\
\hline
\end{tabular}

Detalhamento dos grupos:

- Grupo 01 - Controle de Acesso - Cadastro de Instituições e os Usuários vinculados a elas, definições o papel de cada usuário e as opções que ele tem acesso dentro do sistema.

- Grupo 02 - Estrutura das instituições - Define a estrutura física das Instituições, descrevendo como as mesmas são divididas em Unidade, Setores e Salas. A partir da definição dessa estrutura física é possível vincular uma localização aos equipamentos do EAS.

- Grupo 03 - Gerenciamento dos Equipamentos - Cadastros dos EMH com suas características básicas e o histórico das informações sobre a duração de cada EMH, com suas respectivas manutenções e ordens de serviços.

- Grupo 04 - Fabricante, Modelos e Prestadores - Define os fabricantes e os modelos dos EMH presentes no EAS, além dos prestadores de serviços autorizados a intervir nos equipamentos. 
Na Figura 11 é apresentada a relação entre os grupos funcionais do sistema.
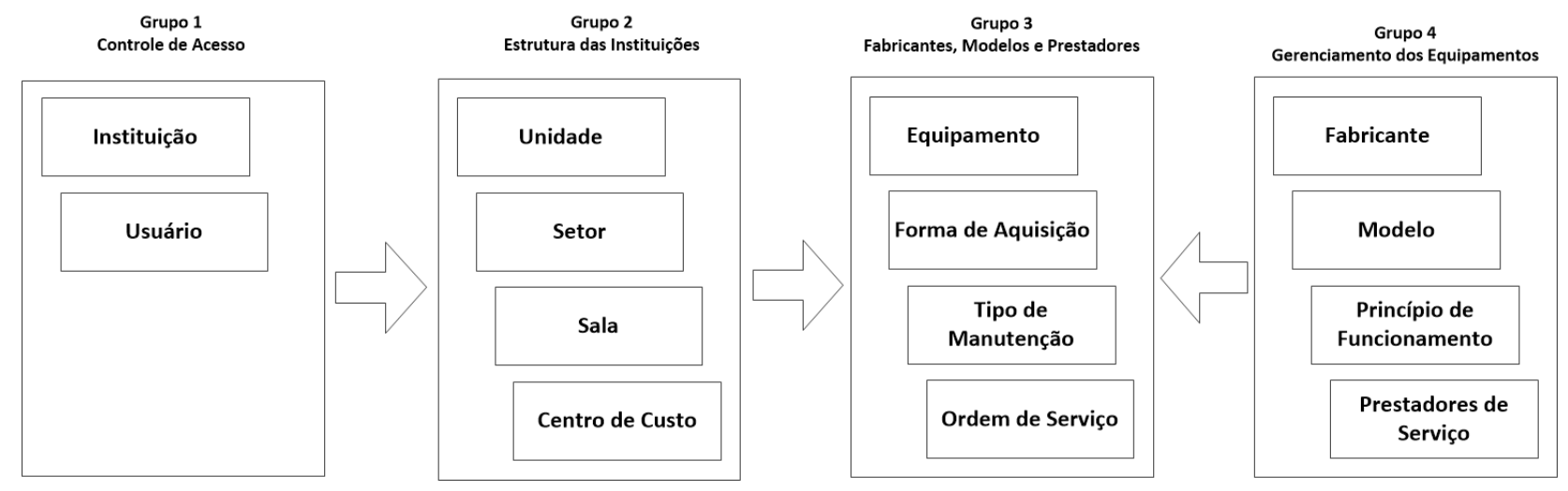

Figura 11 - Grupos Funcionais do Sistema

Com base no detalhamento de cada funcionalidade e o mapeamento das informações que as compõem, foram identificadas as seguintes entidades básicas:

- Instituição

- Usuário

- Centro de Custo

- Unidade

- Usuário x Unidade

- Tipo de Ordem de Serviço

- Forma de Aquisição

- Tipo de Equipamento

- Princípio de Funcionamento

- Fabricante

- Modelo

- Modelo Alerta
- Prestador de Serviço

- Prestador de Serviço x Fabricante

- Impacto do Defeito

- Situação Operacional

- Equipamento

- Equipamento x Alerta

- Solicitação de Serviço

- Atividade da Ordem de Serviço

- Item Financeiro Ordem de Serviço

- Ordem de Serviço

- Ordem de Serviço x Atividade

- Ordem de Serviço x Item Financeiro

A partir das entidades básicas foi construído o modelo de dados que deu origem a estrutura interna do sistema, conforme Figura 12. 


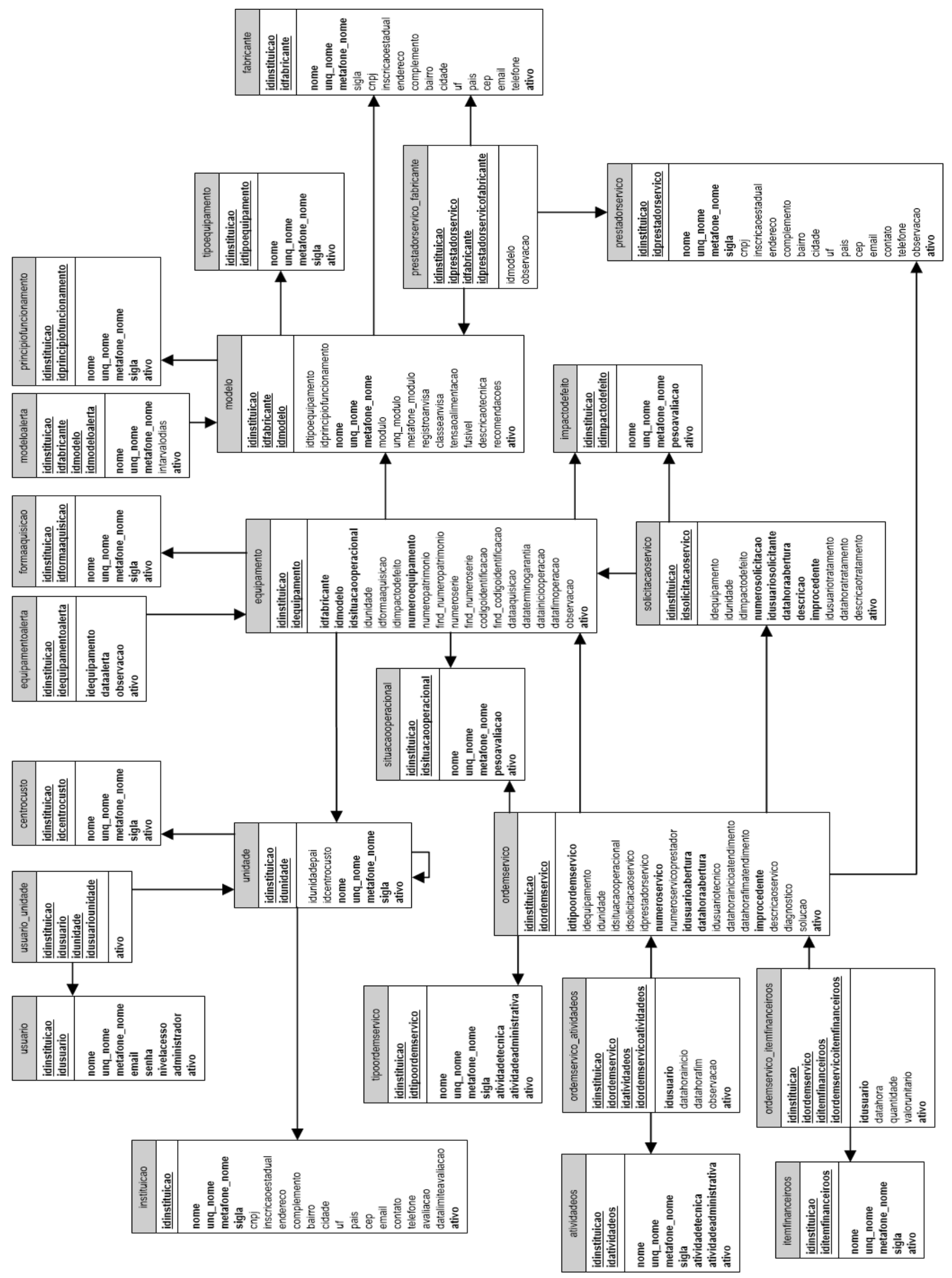

Figura 12 - Modelo de Dados do sistema. 
Para a construção do código do projeto foi utilizada a técnica de Mapeamento Objeto Relacional. Com essa técnica cada tabela/entidade do banco de dados é representada por uma classe na linguagem de programação, no caso Javascript. Foi adotada a correspondência direta entre as tabelas do banco de dados e as classes desenvolvidas em Javasript.

De forma geral, para cada tabela/entidade do banco de dados são geradas três classes Javascript que formam a estrutura central do programa, a Tabela 4 descreve as funcionalidades de cada tipo de classe:

Tabela 4 - Tipos de objetos das entidades do sistema.

\begin{tabular}{l|l}
\hline Tipo de Classe & \multicolumn{1}{c}{ Descrição } \\
\hline Model & $\begin{array}{l}\text { Descreve as propriedades básicas dos objetos, sendo que cada coluna } \\
\text { no banco de dados é convertida em uma propriedade do objeto. } \\
\text { Em cada objeto é incorporada um conjunto padrão de métodos de } \\
\text { validação e persistência de dados. }\end{array}$ \\
\hline View & $\begin{array}{l}\text { Fornece a camada de apresentação do usuário, é composta por métodos } \\
\text { que constroem e gerenciam o funcionamento da interface do usuário. }\end{array}$ \\
\hline Implementa a camada de validação e persistência dos objetos do lado \\
do servidor, fornecendo métodos que permitem a construção da $A P I$ \\
$R E S T F u l$ para troca de dados entre o cliente e o servidor da aplicação.
\end{tabular}

Na Figura 13 é apresentado um fragmento de código da implementação de uma classe Model para a entidade Usuário. Na implementação é possível notar que as propriedades do objeto são as mesmas da tabela de banco de dados apresentada na Figura 12. Em todas as classes do sistema são incorporados um conjunto de métodos, que permite a validação e armazenamento dos dados de forma padronizada. 


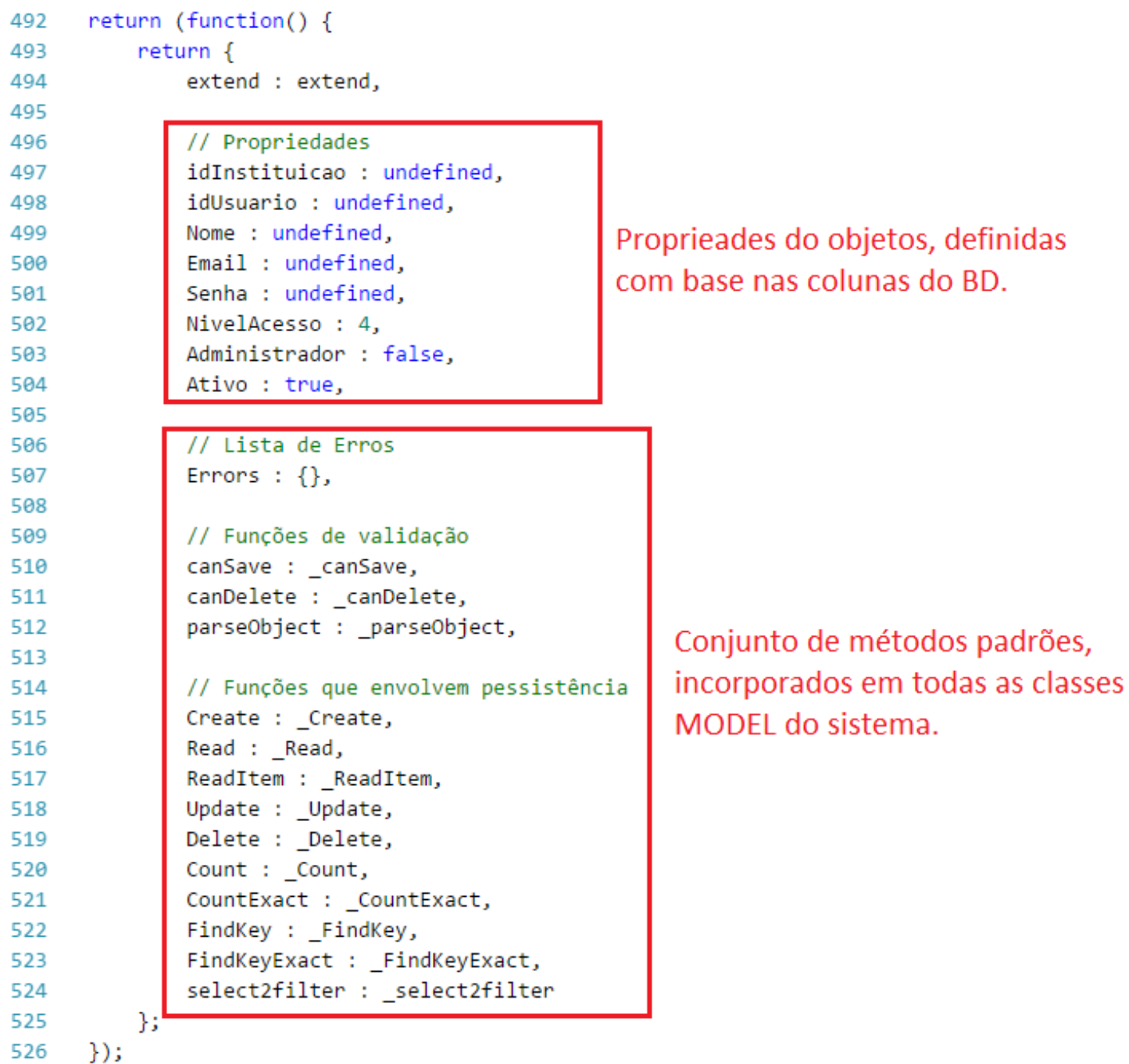

Figura 13 - Fragmento de código da classe Model de Usuário.

\subsection{ESTRUTURA DE DESENVOLVIMENTO DO SERVIDOR $W E B$}

O servidor Web do sistema é composto pelo SGBD PostgreSQL e o servidor de aplicação Node.js. O Node.js recebe e processa as requisições dos clientes, executando a lógica do sistema e garantindo a integridade e segurança dos dados.

Para o desenvolvimento do sistema foi gerada uma base de dados de teste com: 250 instituições, cada instituição com 10 unidades e cada unidade com 300 equipamentos cadastrados, gerando uma base de dados com o total de 1.250.000 equipamentos. Para esse volume de dados os tempos de reposta do servidor se mantiveram abaixo de $1 \mathrm{~s}$, para uma velocidade de conexão $15 \mathrm{MB} / \mathrm{s}$ no cliente, o que demostra que é viável o desenvolvimento do sistema como um serviço $W e b$. 


\subsection{ESTRUTURA DE DESENVOLVIMENTO DO CLIENTE $W E B$}

A interface do cliente Web foi desenvolvida utilizando-se Hypertext Markup Language, Version 5 (HTML5), Cascading Style Sheets (CSS) e a linguagem JavaScript em conjunto com a técnica de desenvolvimento Single Page Application (SPA). A adoção dessas tecnologias permite que o sistema seja utilizado da mesma forma a partir de qualquer navegador internet, nos vários sistemas operacionais como: Microsoft Windows, Android, Linux, $i O S$ e macOS $X$.

\subsection{TELAS/INTERFACE DO SISTEMA E FUNCIONALIDADES}

O sistema foi desenvolvido de forma a ser executado a partir de qualquer navegador internet e em diversos dispositivos, adaptando-se automaticamente as características dos mesmos. É importante ressaltar que o uso do sistema em tablet e/ou smartphones fornece maior mobilidade aos profissionais de EC, o que tem impacto direto no desempenho das suas atividades dentro dos EAS.

Foram estabelecidos padrões de cores na construção da interface de usuário, de modo a facilitar a operação do sistema, principalmente quando há transição da utilização do sistema de um computador desktop para um dispositivo móvel. O uso de um padrão de cores facilita a adaptação do usuário e permite associar a função com os componentes de tela, mesmo quando todas as opções não estão disponíveis no campo visual. A utilização do sistema em alguns dispositivos móveis pode ser comprometida, basicamente em função das telas com menor tamanho, provocando a apresentação excessiva da barra de rolagem e a ocultação automática de menus.

Os padrões adotados nas telas foram:

- Todos os botões terão um texto descrevendo sua funcionalidade e um ícone.

- Botões com a função localizar serão na cor azul.

- Botões com a função de adicionar novo item ao sistema serão na cor verde.

- Botões com a função de edição de um item serão na cor amarela.

- Botões com a função de exclusão de um item será na cor vermelha.

- Botões com a função de salvar o conteúdo de item serão na cor verde.

- Botões com a função de cancelar uma operação serão na cor vermelha. 
- Os resultados de pesquisas serão apresentados em fichas ao invés de tabelas.

- Aos itens de uma lista terão uma barra lateral colorida e cada item terá uma cor diferente para facilitar sua identificação.

- Em função a adequação a dispositivos móveis, cada item terá seu próprio botão de edição e exclusão, de forma a evitar dúvida na utilização da interface.

Outro recurso adotado é a paginação dos dados no retorno das pesquisas, além de reduzir o tráfego de dados evita que o usuário tenha que analisar um grande volume de dados de uma só vez.

\subsubsection{Tela de acesso}

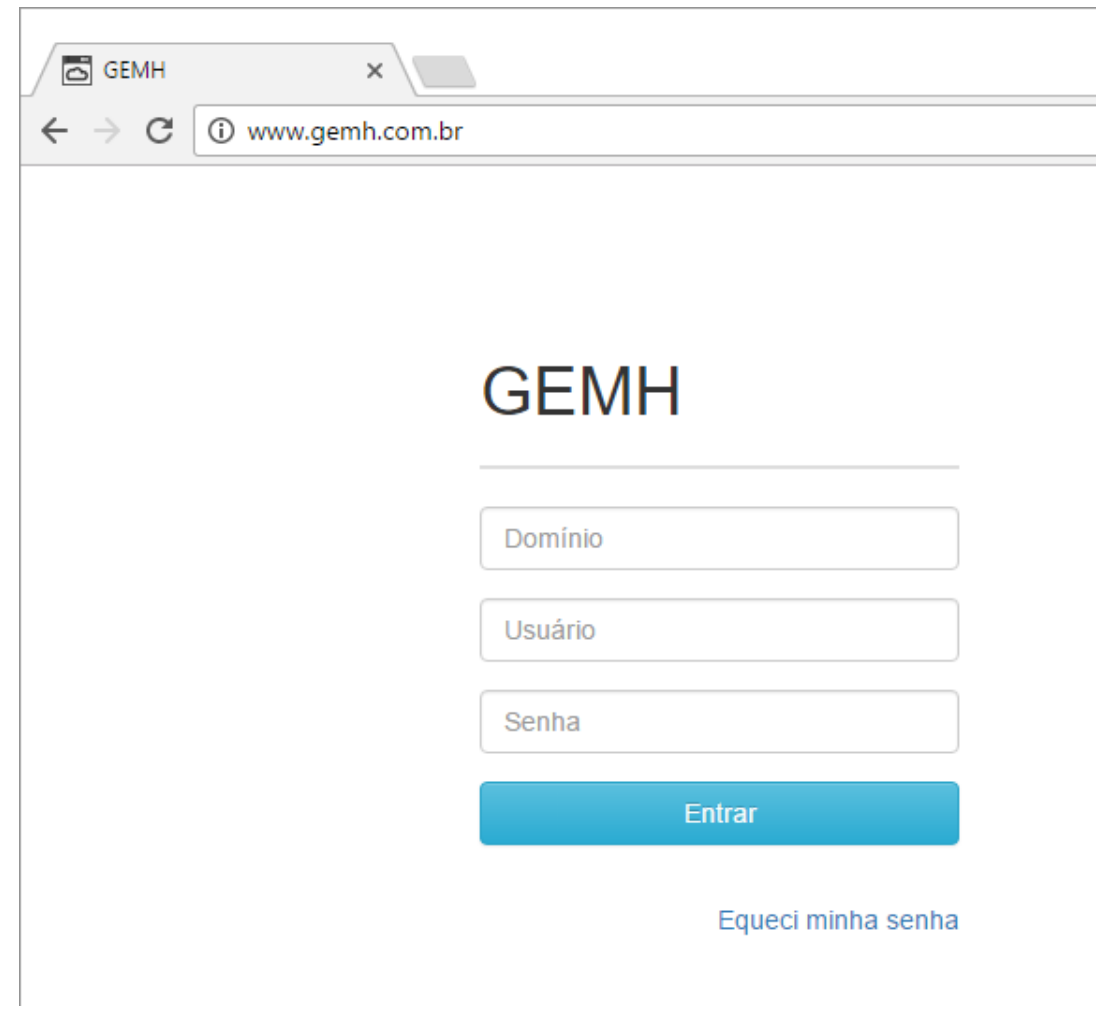

Figura 14 - Tela de acesso.

Ao se acessar a página do sistema é apresentada uma tela de login, conforme Figura 14, onde o usuário deve informar o "Domínio" que é a instituição que ele é vinculado, o "Usuário" e a "Senha”. O campo "Usuário" será sempre um endereço e-mail, pois em caso de necessidade de recuperação da senha a mesma será enviada para o endereço previamente cadastrado. 
Um aspecto importante é que quando um usuário acessa a partir de uma instituição ele não terá acesso aos dados de nenhuma outra instituição, apesar do sistema ser projetado para ser multi-instituição todos os dados são isolados, de forma a manter o sigilo e segurança das informações.

\subsubsection{Tela principal}

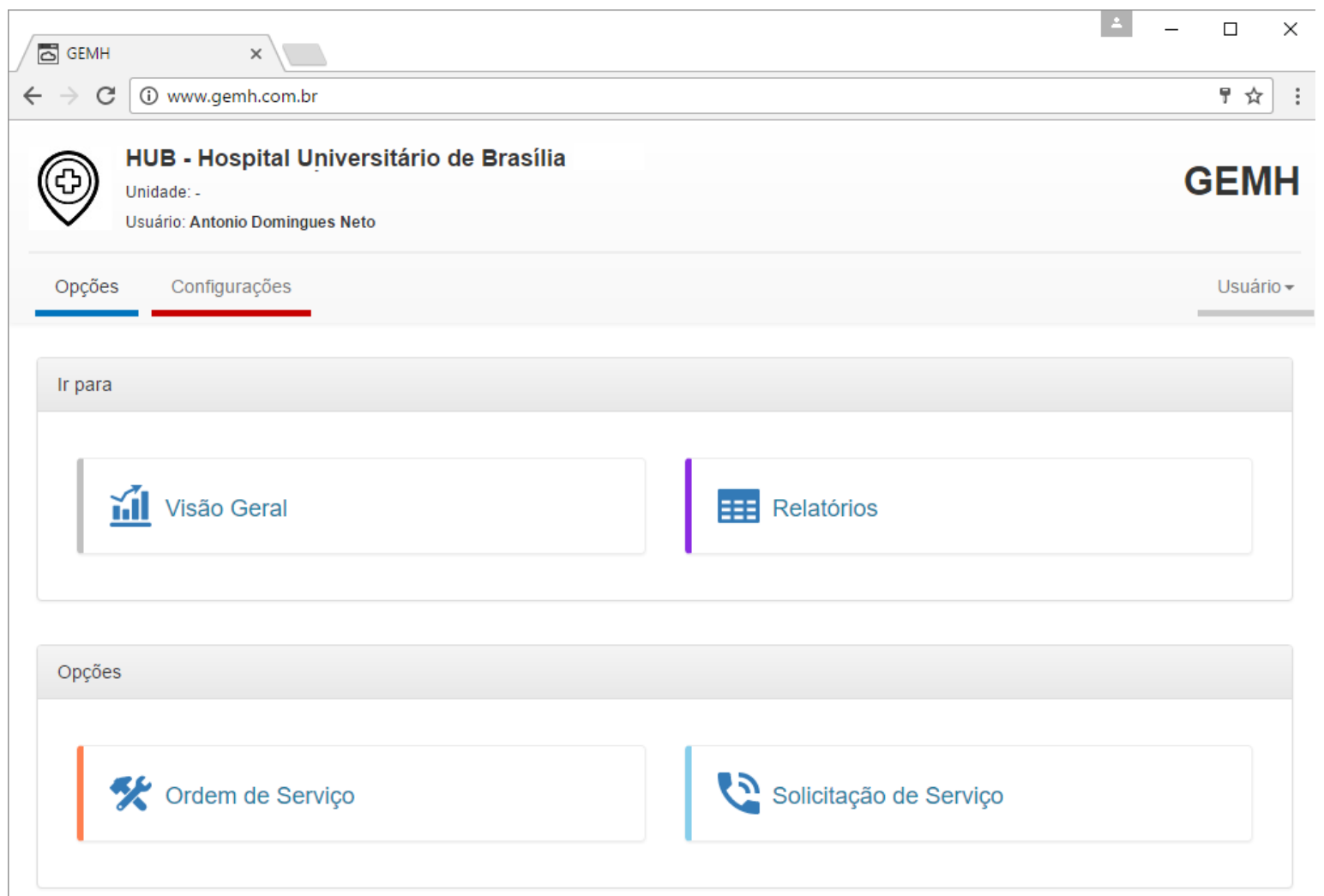

Figura 15 - Tela principal.

Ao entrar no sistema o usuário é apresentada a tela principal do sistema, conforme Figura 15, nela o usuário pode navegar pelas funcionalidades do sistema. Dependendo do perfil do usuário algumas opções podem ser ocultas, estando disponível somente para pessoas com perfis mais elevados.

A definição do perfil de um usuário é realizado pelo administrador do sistema e deve ser adequado as funções desempenhadas pelo usuário. 


\subsubsection{Configurações do sistema}

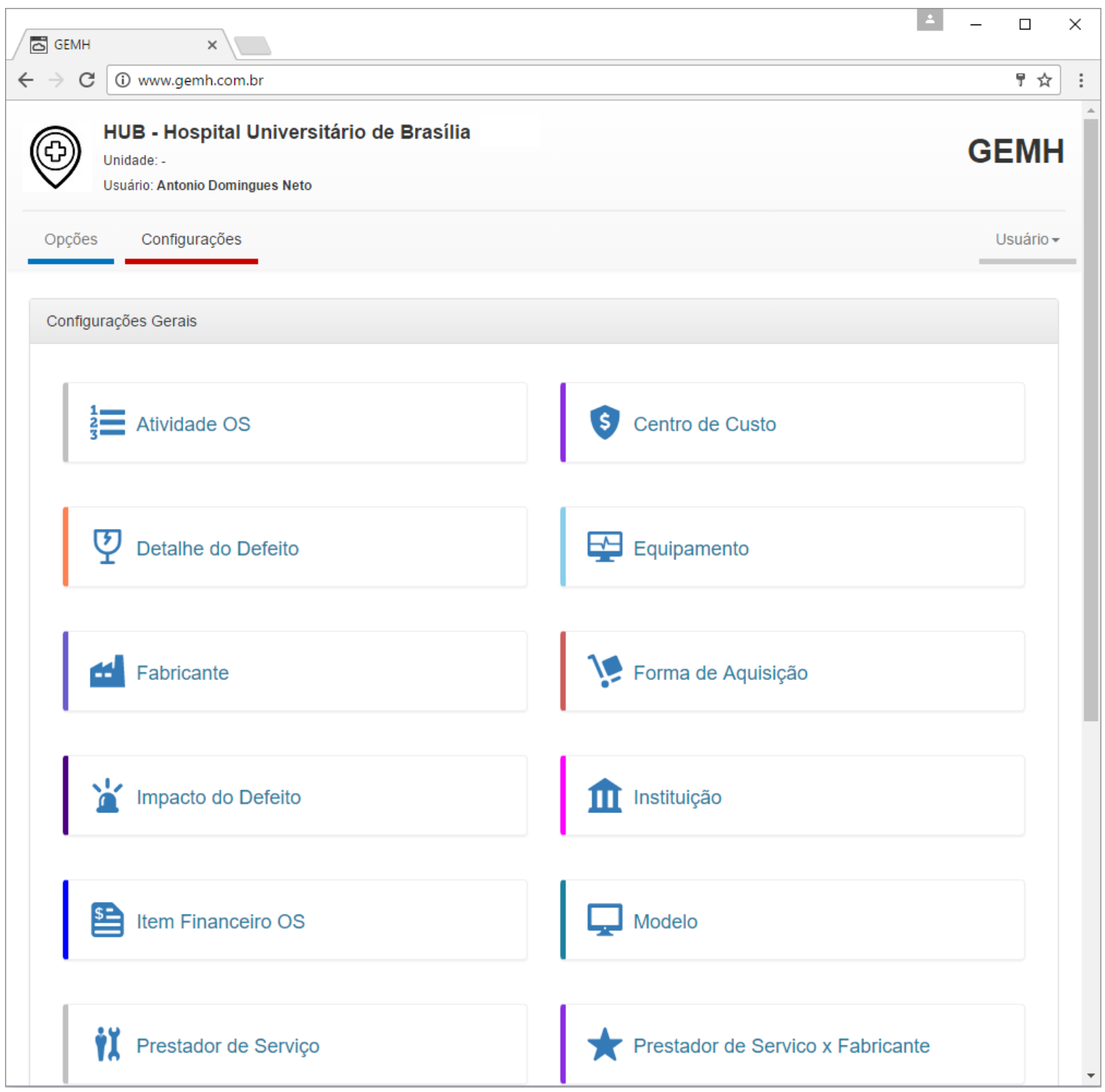

Figura 16 - Tela de configurações do Sistema.

Na tela de configurações do sistema é onde os administradores ajustam o sistema às necessidades da instituição, Figura 16. Antes de iniciar a utilização do sistema é necessário realizar toda uma série de configurações que descrevem os usuários, setores e unidades da instituição. Definir o cadastro de equipamentos a serem geridos com seus respectivos fabricantes e modelos, além de todas as informações que estabelecem as particularidades de cada equipamento. As configurações do sistema são restritas aos usuários com perfis de administradores e gerentes do sistema. 


\subsubsection{Navegadores de dados}

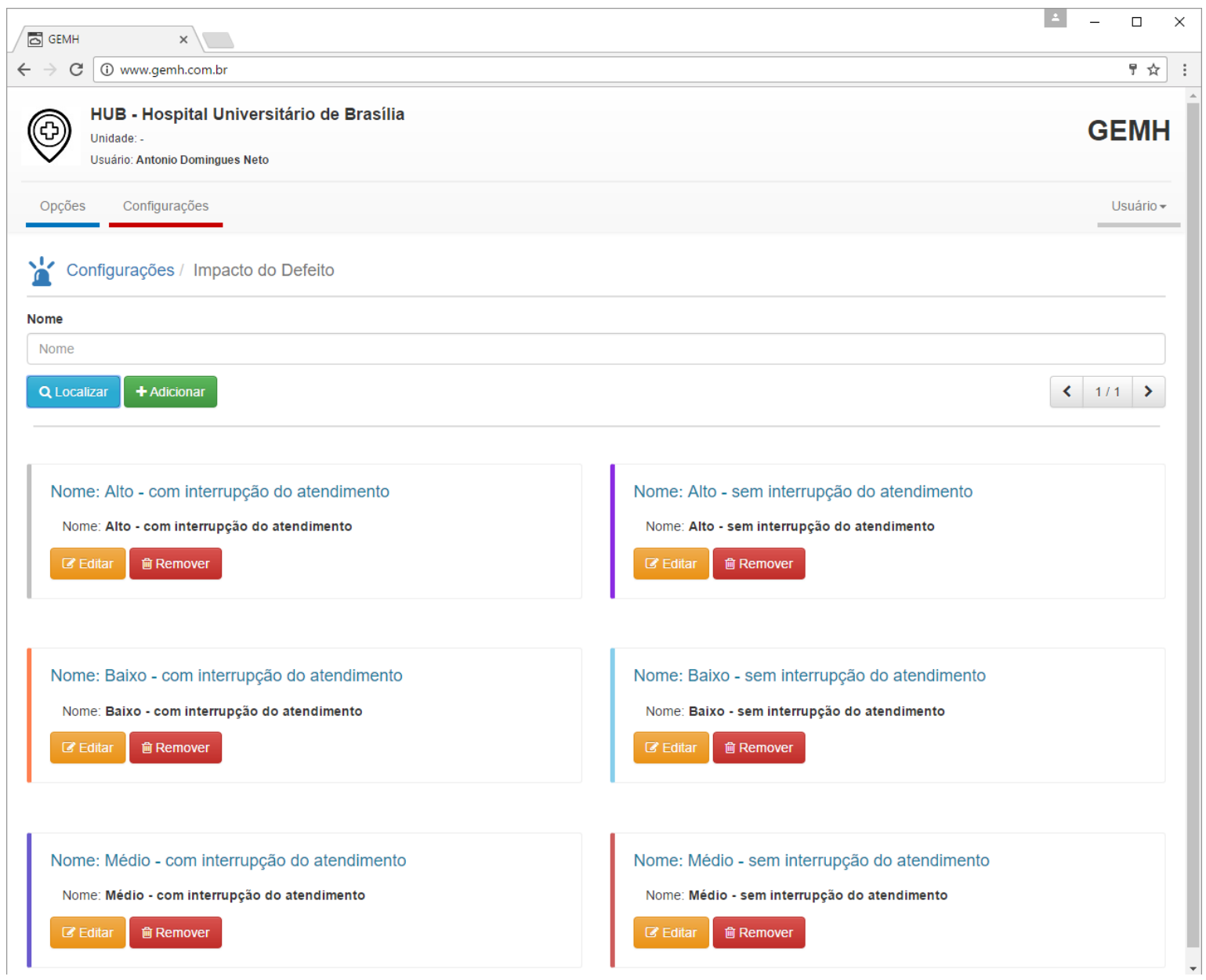

Figura 17 - Tela de navegador de dados para Impacto do Defeito.

Para facilitar a operação do sistema foi estabelecido o conceito de navegadores de dados para as telas de configurações, conforme Figura 17. O objetivo das telas de navegadores de dados é fornecer uma forma padronizada de utilização do sistema e que se adeque de forma consistente a qualquer dispositivo de visualização. 


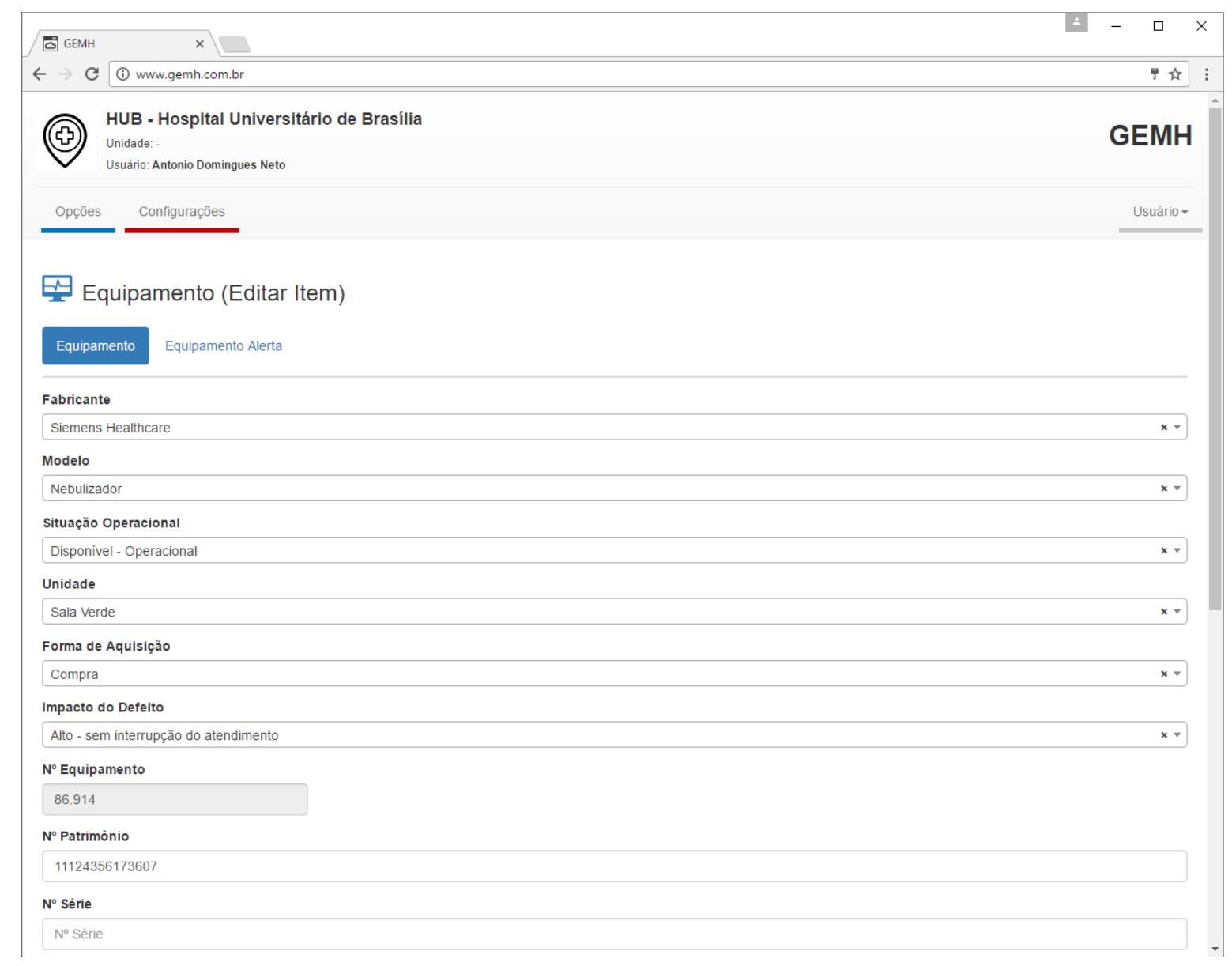

Figura 18 - Tela de Equipamentos.

Na tela de equipamento é possível cadastrar os detalhes de um equipamento, Figura 18, tais como fabricante, modelo, situação operacional, unidade, número de série, entre outros.

Um equipamento pode ser identificado por alguns códigos específicos, que são: número de série, número de patrimônio e código de identificação. $\mathrm{O}$ número de série é o número fornecido pelo fabricante e normalmente está fixado no corpo do equipamento. $\mathrm{O}$ número de patrimônio é o número relacionado ao controle patrimonial da instituição, normalmente é global a todos os ativos da empresa. O código de identificação é um código alfanumérico único associado ao equipamento, a criação deste código deve seguir as diretrizes da EC, com este campo é possível associar uma etiqueta RFID a um equipamento, permitindo automatizar a gestão dos EMH. 
Para vinculação de um código presente em uma etiqueta RFID a um equipamento é necessário seguir os seguintes passos:

1. Selecionar uma nova etiqueta a ser associada ao equipamento.

2. Abrir a tela de cadastro do equipamento.

3. Posicionar o cursor no campo Código de Identificação.

4. Pressionar o botão de leitura da etiqueta, indicado na Figura 19.

5. Salvar os dados.

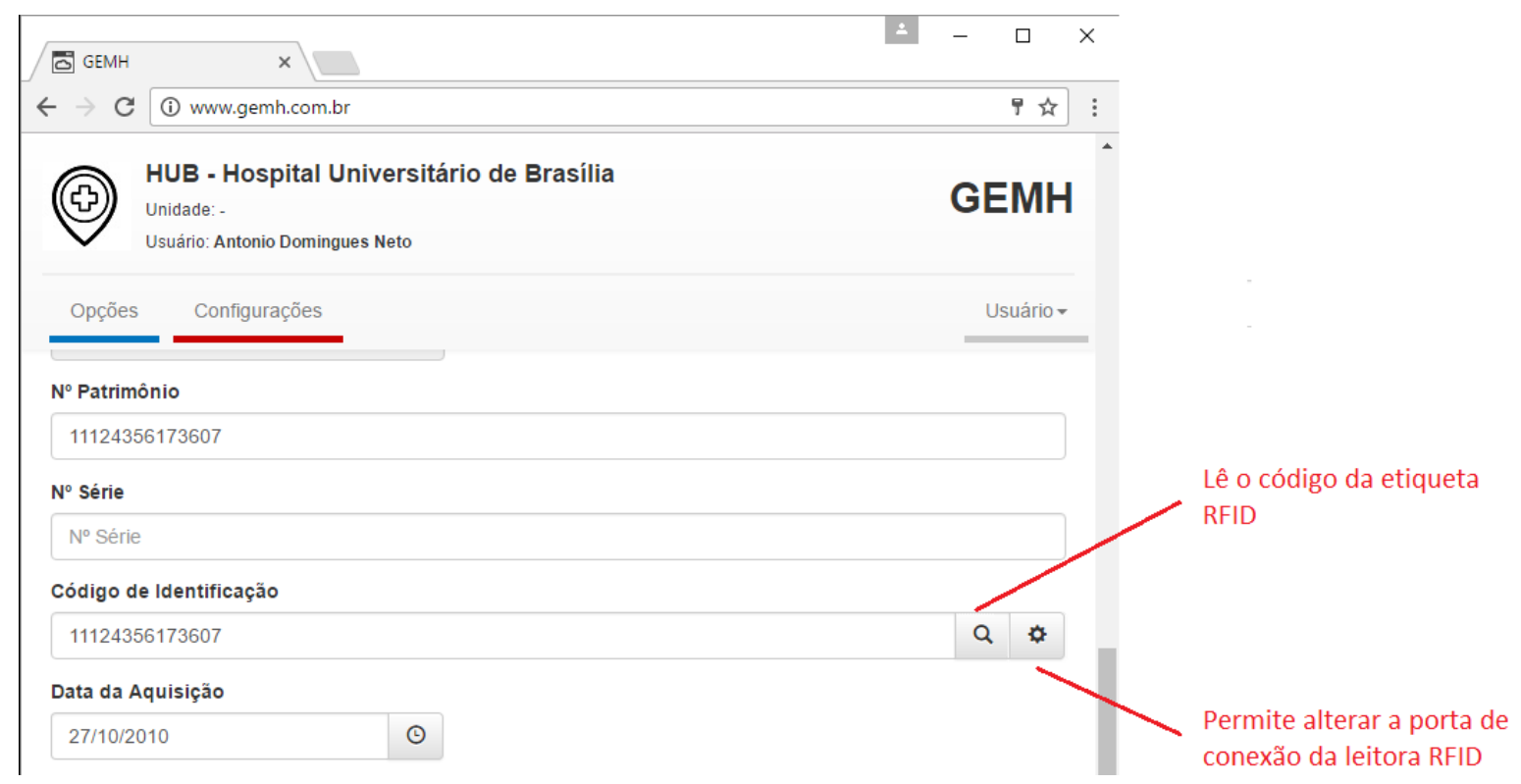

Figura 19 - Associar uma etiqueta RFID a um equipamento.

Com o uso de etiquetas RFID é possível agilizar o processo de inventário do parque de equipamentos EMH, minimizar os erros de digitação e dar maior segurança na execução do processo de inventário e gestão nos EAS. 


\subsubsection{Tela de Solicitação Serviço}

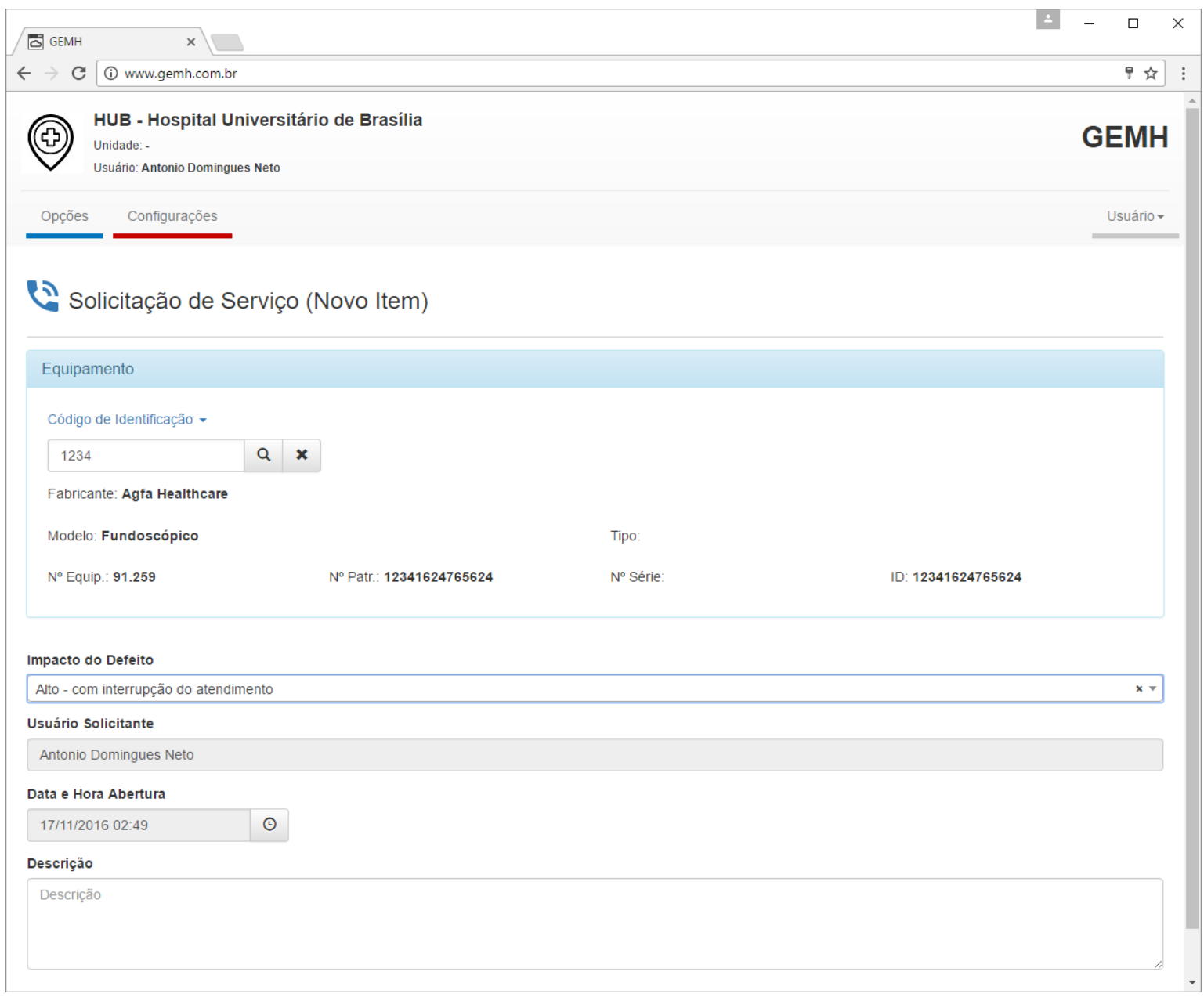

Figura 20 - Tela de Solicitação de Serviço.

Permite o solicitar a execução de um serviço para um equipamento, a tela segue o mesmo padrão de interface adotado em todo o sistema, conforme pode ser observado na Figura 20.

\subsubsection{Outras funcionalidades do sistema}

O sistema apresenta um conjunto completo de funcionalidades voltado para a gestão de $\mathrm{EMH}$, sendo que nem todas foram detalhadas, que envolvem vários cadastros, relatórios e gráficos. Estas funcionalidades foram estabelecidas com base nas recomendações da ANVISA e tem o objetivo de fornecer uma ferramenta adequada aos departamentos de EC dos EAS. 


\subsection{PROJETO DO LEITOR RFID}

Tendo em vista que a proposta do projeto é a implementação de um sistema Web para gestão de EMH, acessível para os mais diversos EAS, com o uso da tecnologia RFID. O custo dos leitores de tags RFID móveis, que permitiriam maior mobilidade dos profissionais de EC, se mostrou uma barreira, uma vez que podem ter um custo de mais de $\mathrm{R} \$ 5.000,00$ (cinco mil reais), o que torna inviável a utilização dessa característica do sistema. Para solucionar este problema foi desenvolvido um leitor de RFID com a plataforma Arduino, abrindo a possibilidade de que mais EAS possam adotar a solução por completo.

Com o desenvolvimento do leitor RFID a partir da plataforma Arduino foi possível construir um protótipo totalmente funcional com o valor total de $\mathrm{R} \$ 116,40$ (cento e dezesseis reais e quarenta centavos), não sendo considerado o custo de projeto e montagem. O protótipo permite a leitura de tags RFID que operam na frequência de 13,53 $\mathrm{MHz}$, esta frequência se mostrou a mais adequada para características do sistema, sendo que a conexão com o computador é realizada via bluetooth,. A cada leitura o código presente na tag RFID é enviado para o dispositivo conectado ao leitor, que pode ser um computador ou tablet.

Com a possibilidade do uso do sistema a partir de dispositivos móveis os departamentos de EC ganham agilidade e mobilidade na manipulação das informações dos EMH, como no processo de inventário do parque tecnológico e na consulta de relatórios e dados estatísticos.

Foi projetado e construído um leitor RFID para etiquetas passivas a partir da plataforma Arduino, sendo utilizados os seguintes componentes, conforme descrito na Tabela 5: 
Tabela 5 - Lista de componentes do protótipo do Leitor RFID.

Valores obtidos no site http://www.tdtec.com.br em 01/10/2016

\begin{tabular}{|c|c|c|}
\hline Item & Especificação & Valor \\
\hline Arduino Nano & 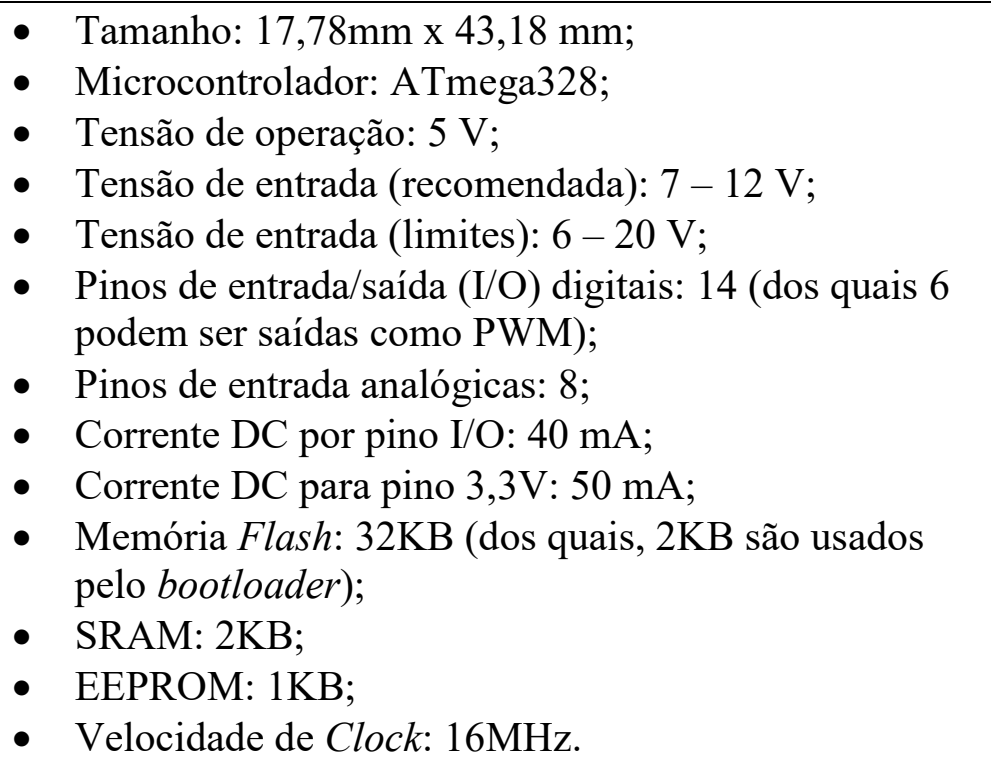 & $\mathrm{R} \$ 17,80$ \\
\hline $\begin{array}{l}\text { Módulo } \\
\text { Sensor } \\
\text { Bluetooth } \\
\text { RS232 }\end{array}$ & 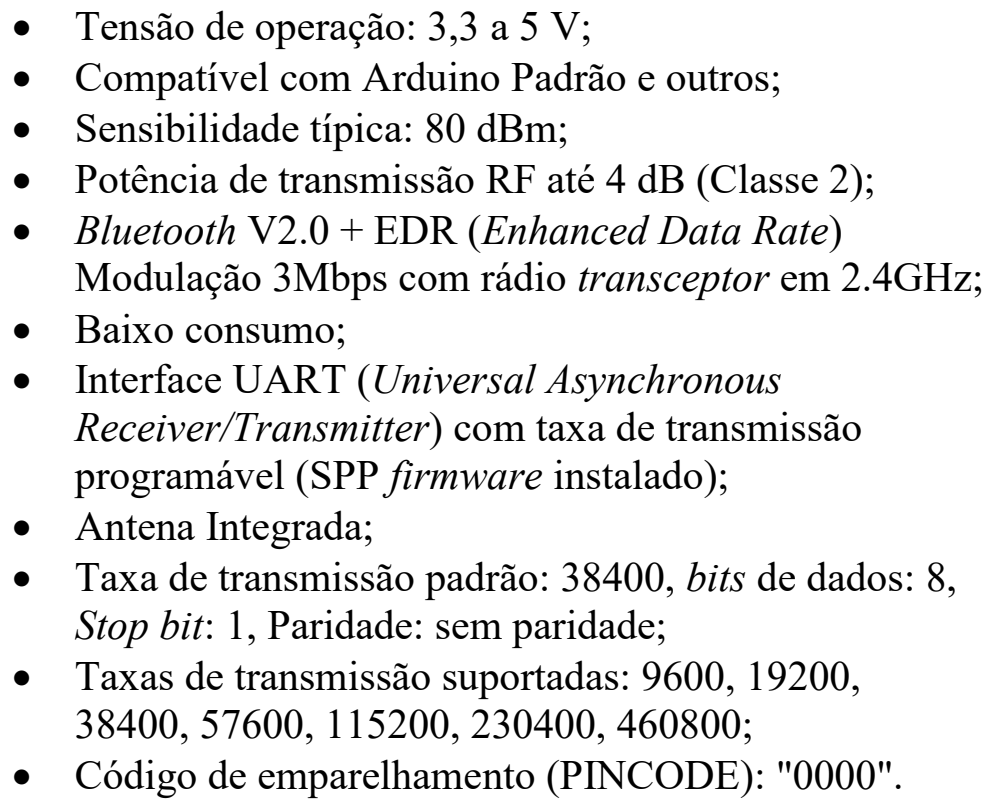 & $\mathrm{R} \$ 34,90$ \\
\hline $\begin{array}{l}\text { Kit Leitor } \\
\text { RFID RC522 } \\
13.56 \mathrm{MHz}\end{array}$ & $\begin{array}{ll}\text { - } & \text { Tensão de operação: DC } 3,3 \mathrm{~V} \text {; } \\
\text { - } & \text { Corrente de operação: } 13-26 \mathrm{~mA} ; \\
\text { - } & \text { Corrente em repouso: } 10-13 \mathrm{~mA} / 3.3 \mathrm{~V} ; \\
\text { - } & \text { Corrente de pico: < } 30 \mathrm{~mA} ; \\
\text { - } & \text { Frequência de operação: } 13,56 \mathrm{Mhz} ; \\
\text { - } & \text { Tipos de cartões suportados: MIFARE1 S50, } \\
& \text { MIFARE1 S70, MIFARE UltraLight, MIFARE Pro, } \\
& \text { MIFARE DESFire; } \\
\text { - } & \text { Temperatura de operação: }-20 \text { a } 80^{\circ} \mathrm{C} ;\end{array}$ & $\mathrm{R} \$ 33,90$ \\
\hline
\end{tabular}




\begin{tabular}{|c|c|c|}
\hline & $\begin{array}{l}\text { - Temperatura ambiente: }-40 \text { a } 85^{\circ} \mathrm{C} \text {; } \\
\text { - Umidade relativa: } 5 \%-95 \% \text {; } \\
\text { - Interface de comunicação: SPI (Serial Peripheral } \\
\text { Interface); } \\
\text { - Taxa de transferência de dados: máx. } 10 \mathrm{Mbit} / \mathrm{s} \text {; } \\
\text { - Dimensões: } 40 \text { x } 60 \mathrm{~mm} \text {; } \\
\text { - Peso: } 22 \mathrm{~g} \text {. }\end{array}$ & \\
\hline $\begin{array}{l}\text { Placa de } \\
\text { Padrão }\end{array}$ & - $\quad$ Placa padrão perfurada para solda. & $\mathrm{R} \$ 8,00$ \\
\hline $\begin{array}{l}\text { Conector } \\
\text { Bateria 9V }\end{array}$ & - Suporte rabicho para bateria $9 \mathrm{~V}$. & $\mathrm{R} \$ 1,00$ \\
\hline Bateria 9V & - $\quad$ Bateria 9V Ultrapower. & $\mathrm{R} \$ 4,50$ \\
\hline LED RGB & - $\quad$ LED RGB. & $\mathrm{R} \$ 2,50$ \\
\hline $\begin{array}{l}\text { Botão push } \\
\text { button }\end{array}$ & - Chave push button. & $\mathrm{R} \$ 3,00$ \\
\hline Botão On/Off & - Botão On/Off & $\mathrm{R} \$ 1,00$ \\
\hline $\begin{array}{l}\text { Alto-falante } \\
\text { Buzzer }\end{array}$ & - Alto-falante - Buzzer Mangético não auto-oscilante. & $\mathrm{R} \$ 1,80$ \\
\hline Caixa Plástica & - Caixa Plástica Patola & $\mathrm{R} \$ 8,00$ \\
\hline \multicolumn{2}{|c|}{ VALOR TOTAL } & $\mathrm{R} \$ 116,40$ \\
\hline
\end{tabular}

Na Figura 21 é apresentada a disposição dos módulos na montagem do protótipo do leitor RFID.

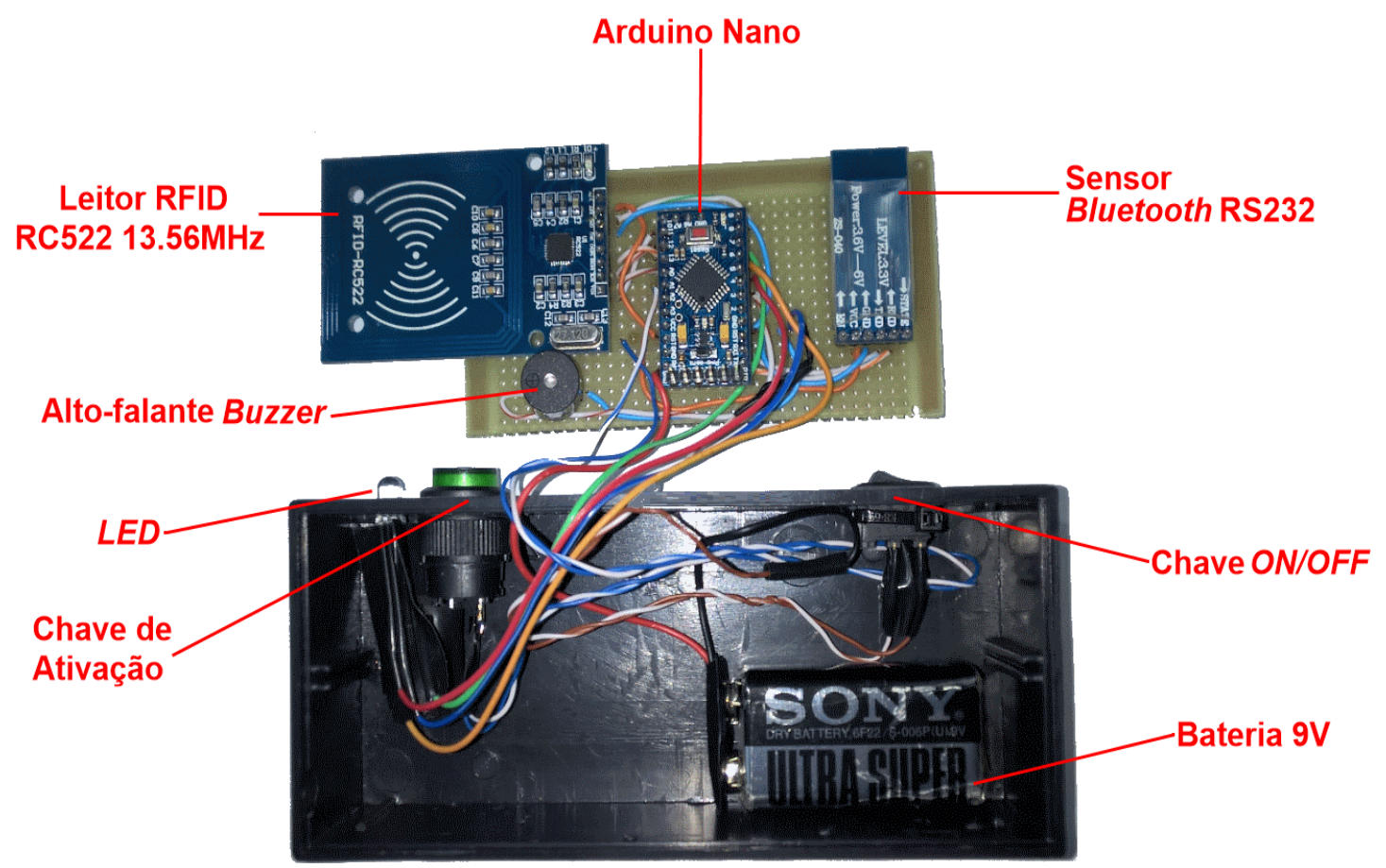

Figura 21 - Protótipo do Leitor RFID com Arduino. 
O processo de leitura se inicia ao pressionar o botão de ativação, nesse momento é emito um alerta sonoro curto e o led é aceso com a cor verde, indicando que o leitor está apto a realizar a leitura. Ao se aproximar o leitor de uma etiqueta e o código da mesma é lido corretamente, um alerta sonoro longo é emitido, o led é apagado e o código da etiqueta é enviado via bluetooth, para o computado no qual o leitor está conectado. Caso ocorra erro leitura será emitido um alerta sonoro duplo e o led é aceso na cor vermelha, indicando que a leitura deve ser repetida.

\subsection{ESTUDO DE CASO}

O sistema está em fase de implantação em um EAS de médio porte, que possui: 100 leitos, 3 sala cirúrgicas, 2 salas de hemodinâmica, Ambulatório e Emergência. O departamento de EC do EAS utiliza um software de gestão de patrimônio genérico, para gestão do parque de EMH. A Tabela 6 apresenta os dados dos EMH presentes no sistema de patrimônio.

Tabela 6 - Equipamentos do EAS (Estudo de Caso)

\begin{tabular}{c|l}
\hline Quantidade & Item \\
\hline 2.304 & Equipamentos \\
\hline 345 & Modelos \\
\hline 147 & Fabricantes \\
\hline 32 & Setores \\
\hline 139 & Tipos de Equipamentos \\
\hline
\end{tabular}

Foi feita uma análise dos registros dos 2.304 EMH no sistema de patrimônio e foram identificados vários problemas. A Tabela 7 descreve os problemas encontrados no cadastro.

Tabela 7 - Problemas do cadastro dos EMH (Estudo de Caso)

\begin{tabular}{c|l|c}
\hline Quantidade & \multicolumn{1}{|c}{ Item } & Percentual \\
\hline 115 & Sem Número de Série e Número de Patrimônio & $5,0 \%$ \\
\hline 87 & Sem identificação do Fabricante & $3,8 \%$ \\
\hline 209 & Sem identificação do Modelo & $9,0 \%$ \\
\hline 366 & Sem identificação do Tipo de Equipamento & $15,9 \%$ \\
\hline 43 & $\begin{array}{l}\text { Sem identificação do Fabricante, Modelo e Tipo } \\
\text { de Equipamento }\end{array}$ & $1,9 \%$ \\
\hline 65 & Sem identificação de Setor & $2,8 \%$ \\
\hline
\end{tabular}


Outros problemas encontrados foram:

- Número de patrimônio inconsistente e/ou indicação da existência de número de patrimônio, porém não há a etiqueta de identificação junto ao equipamento;

- Falta de cadastro de número de série;

- Equipamentos associados a setores que não correspondem à realidade;

- Associação errada entre modelos e fabricantes;

- Falta de padronização no cadastramento dos itens.

Com a utilização do sistema, específico para gestão EMH, vários desses problemas não ocorrem ou são minimizados, tendo em vista que para o início da utilização operacional do sistema é necessário definir relações consistentes entre: unidades e setores, fabricantes e modelos, unidades e usuários, entre outros. $\mathrm{O}$ problema de não preenchimento de campos é evitado com a obrigatoriedade do preenchimento de campos específicos ou com a emissão de alertas/relatórios, indicando o não preenchimento de determinadas informações.

Durante a implantação foram verificadas algumas diferenças cruciais entre o sistema desenvolvido e o sistema genérico de gestão de patrimônio, tais como: obrigatoriedade de um cadastro detalhado dos equipamentos (com dados dos fabricantes e modelos), controles sobre calibração e manutenções preventivas, alertas para término da vida útil e descarte dos equipamentos, conforme descrito na legislação estabelecida pela ANVISA. Outra característica importante foi o acesso ao sistema a partir de dispositivos móveis, que agiliza o atendimento das ordens de serviços, reduz a utilização de formulários impressos e permite que os gestores possam acompanhar as atividades da EC, mesmo quando não estão fisicamente presentes no EAS. 


\section{DISCUSSÃO E CONCLUSÃO}

A gestão do parque dos EMH é uma necessidade antiga dos EAS. Porém, essa necessidade se torna prioridade a partir do ano de 2010, quando a ANVISA estabelece uma legislação que define que todos os estabelecimentos de saúde devem realizar o gerenciamento das tecnologias em saúde utilizadas na prestação de seus serviços, desde sua entrada no estabelecimento até seu destino final, incluindo o planejamento dos recursos físicos, materiais e humanos (ANVISA, 2010).

Tendo por base os critérios estabelecidos na legislação, foi proposto e desenvolvido um sistema que permite a gestão dos EMH pelos EAS. Visando que o sistema possa atender a necessidade do maior número possível de EAS, foram estabelecidos critérios de gestão que atendam a legislação em vigor, contudo sem que seja imposta uma mudança radical na rotina dos departamentos de EC dos EAS.

Foram identificadas as informações mínimas que um EAS deve gerir para atender a legislação, que são:

- Dados do próprio estabelecimento: Informações básicas da própria instituição de saúde e estrutura física/locais onde os equipamentos estão distribuídos.

- Dados básicos dos equipamentos: Dados que descrevem um equipamento, como: fabricante, modelo, tipo de equipamento, forma de aquisição, princípio de funcionamento, impacto dos defeitos e a situação operacional.

- Dados históricos do equipamento: rotina de manutenção dos equipamentos, intervenções que sejam necessárias, treinamentos, ocorrência de manutenções corretivas e preventivas, entre outras.

Além dessas informações mínimas também foram consideradas situações comuns nos EAS, tais como:

1. Instituições de porte médio e grande normalmente têm bem definidas as suas estruturas física, porém instituições menores a estrutura nem sempre é definida, o que dificulta a localização dos equipamentos ou mesmo a associação de um defeito ou falha ao ambiente, como por exemplo uma falha elétrica.

2. Foi observado que nem sempre as instituições possuem informações básicas sobre os equipamentos, o que dificulta muito a gestão. Informações básicas 
como fabricante e modelo não são aparentes, além de não haver qualquer registro de compra ou desde quando o equipamento faz parte do parque do EAS. Também é comum o desconhecimento do impacto causado pela quebra ou ausência de um equipamento.

3. É comum que não haja histórico de todas as intervenções técnicas que um equipamento foi submetido, normalmente esta é gestão é feita somente durante o prazo de garantia de compra ou durante o prazo de garantida da última manutenção.

4. Nem todo EAS possui uma infraestrutura de TI ou capacidade de investimento para montar a estrutura de necessária para a implantação de um sistema de informação.

5. Existem disponíveis no mercado alguns sistemas para gestão de equipamentos, tanto gratuitos como pagos, porém ou não são projetados especificamente para EMH e por isso nem sempre atendem os requisitos da legislação, ou são sistemas comerciais que apresentam um custo muitas vezes proibitivo, principalmente para as EAS de menor porte.

Considerando os requisitos mínimos de um sistema de gestão de EMH e as dificuldades encontradas pelos EAS, observa-se que o sistema proposto vai de encontro com a necessidade do mercado.

A implementação do projeto se mostrou viável técnica e economicamente para as tecnologias adotadas.

Logo, a construção do sistema de gestão específico para EMH, seguindo a legislação da ANVISA, como um serviço Web e com acesso gratuito, é um diferencial. Viabilizando a gestão para os EAS de pequeno porte, sem impor novos custos operacionais. Apresentando a vantagem do uso do sistema a partir de dispositivos móveis, que dão aos departamentos de EC agilidade e mobilidade na manipulação das informações, como no processo de inventário do parque tecnológico e na consulta de relatórios e dados estatísticos, fornecendo uma maior perspectiva da gestão do EMH. 


\section{TRABALHOS FUTUROS}

Como trabalhos futuros, sugerem-se os seguintes:

1 A avaliação da utilização de etiquetas ativas;

2 Formação de uma rede de EAS, compartilhando as informações sobre incidentes técnicos do EMH.

3 Com a utilização do sistema nos EAS seria possível avaliar os aspectos operacionais dos $\mathrm{EMH}$, permitindo estudos na área de gestão financeira e operacional, planejamento da EC, gestão de processos e pessoas, etc.

Em relação à primeira sugestão, existe a intenção de avaliar a utilização de etiquetas ativas, onde os equipamentos enviariam para o sistema suas localizações físicas para monitoramento automático do parque tecnológico, com a possibilidade da emissão de alarmes em casos de extravios ou roubos.

Para a segunda sugestão, seria proposta a formação de uma rede de EAS aonde seriam compartilhadas as informações estatísticas sobre eventos adversos envolvendo EMH, ou a possibilidade de verificação dos índices de defeito de um EMH de uma marca e modelo (dando subsídio para os administradores dos EAS na hora da aquisição de novos equipamentos). 


\section{REFERÊNCIAS BIBLIOGRÁFICAS}

ANVISA. Segurança do Paciente, 2010. Disponivel em: <http://www20.anvisa.gov.br/ segurancadopaciente/index.php/legislacao/item/rdc-2-de-25-de-janeiro-de-2010>. Acesso em: 01 mar. 2016.

ANVISA, 2010. Disponivel em: <http://www20.anvisa.gov.br/segurancadopaciente/ index.php/legislacao/item/rdc-2-de-25-de-janeiro-de-2010>. Acesso em: 01 mar. 2016.

ANVISA. Boas Práticas em Serviços de Saúde Legislações, 2010. Disponivel em: $<$ http://www20.anvisa.gov.br/segurancadopaciente/index.php/legislacao/item/rdc-2-de-25de-janeiro-de-2010>. Acesso em: 01 out. 2016.

ANVISA. Boas Práticas em Serviços de Saúde Legislações, 2011. Disponivel em: $<$ http://www20.anvisa.gov.br/segurancadopaciente/index.php/legislacao/item/rdc-63-de25-de-novembro-de-2011>. Acesso em: 01 out. 2016.

CALIL, S. J.; TEIXEIRA, M. S. Gerenciamento de Manutenção de Equipamentos Hospitalares. São Paulo: Faculdade de Saúde Pública da Universidade de São Paulo, 1998.

CNES. CnesWEB - Cadastro Nacional de Estabelecimentos de Saúde. CNESNet Secretária de Atenção à Saúde, 2016. Disponivel em: $<$ http://cnes2.datasus.gov.br/Lista_Tot_Es_Estado.asp>. Acesso em: 30 abr. 2016.

DAR, U. PostgreSQL Server Programming. 2nd Revised. ed. [S.1.]: Packt Publishing, 2015 .

DATASUS. DATASUS. Portal da Saúde, 2016. Disponivel em: $<$ http://www2.datasus.gov.br/DATASUS/index.php?area=01>. Acesso em: 30 abr. 2016.

FERREIRA, E.; EIS, D. HTML5 - Curso W3C Escritório Brasil. [S.1.]: [s.n.], 2014.

FLANAGAN, D. Javascript - O guia definitivo. 6ª ed. ed. Porto Alegre: Bookman, 2013.

GLOVER, B.; BHATT, H. Fundamentos de RFID. Rio de Janeiro: Alta Books, 2007. 
HERMINI, A. H. A tecnologia e sua relação com os procedimentos assistenciais de saúde. São Paulo: Saraiva, 2013.

LAHIRI, S. RFID Sourcebook. [S.1.]: IBM Press, 2006.

MANISH, B.; SHAHRAM, M. RFID Field Guide: Deploying Radio Frequency Identification Systems. [S.1.]: Prentice Hall, 2005.

MINISTÉRIO DA SAÚDE. Equipamentos Médico-Hospitalares e o Gerenciamento da Manutenção: capacitação adistância. Brasília: REFORSUS, 2002.

MINISTÉRIO DA SAÚDE. Guia para elaboração do plano de gestão de equipamentos para serviços de Hematologia e Hemoterapia. Brasília: Ministério da Saúde, 2012.

MONK, S. 30 Projetos com Arduino. 2a ed. ed. [S.1.]: Bookman, 2014.

MONTEIRO, F. Learning Single-page Web Application Development. [S.1.]: Packt Publishing, 2014.

NODEJS, 2016. Disponivel em: <https://nodejs.org>. Acesso em: 01 mar. 2016.

POSTGRESQL, 2016. Disponivel em: <http://www.postgresql.org>. Acesso em: 01 mar. 2016.

PRESSMAN, R. Engenharia de Software. $7^{\text {a }}$ ed. ed. Porto Alegre: AMGH Editora Ltda, 2011.

SWEENEY, P. J. RFID for Dummies - A Reference for the Rest of Us. Indianápolis: Wiley Publishing Inc, 2007.

W3C ESCRITÓRIO BRASIL. Curso W3C Escritório Brasil. [S.1.]: [s.n.], 2014. 
ANEXO 


\title{
ANEXO 1: PUBLICAÇÕES
}

\section{DESENVOLVIMENTO DE UM SISTEMA WEB PARA GESTÃO DE EQUIPAMENTOS MÉDICO-HOSPITALARES}

\author{
Antonio Domingues Neto * e José Felício da Silva* \\ *Programa de Pós Graduação em Engenharia Biomédica da Universidade de Brasília (UnB) \\ Faculdade Gama (FGA), Brasil \\ e-mail: antoniodn@gmail.com
}

Resumo: Com base nos grandes desafios que os Estabelecimentos Assistenciais de Saúde (EAS) encontram na gestão do parque de Equipamentos Médico-Hospitalares (EMH), é proposto um sistema $W E B$ que viabiliza e simplifica a implantação de procedimentos de controle nas instituições. O sistema é uma plataforma na qual os EAS registram as informações do parque tecnológico de equipamentos médico-hospitalares, que pode ser acessada de qualquer terminal conectado à internet. $\mathrm{O}$ sistema seguirá os mesmos princípios de um serviço $W E B$, como os webmails, onde a instituição cria uma conta e passa a ter acesso a todos os recursos de gestão. $\mathrm{O}$ sistema foi desenvolvido utilizando as tecnologias HTML, CSS e JavaScript, para implementação da interface do cliente. É utilizado o banco de dados PostgreSQL, Node.js como servidor de requisições e JavaScript para o desenvolvimento da lógica de controle do serviço. A implementação de um sistema de gestão de EMH como um serviço $W E B$, se mostra viável e acessível para os mais diversos EAS.

Palavras-chave: Equipamentos Médico-Hospitalares, Engenharia Clínica, Gestão de Equipamento, Sistema $W E B$.

Abstract: Based on the great challenges that the Health Care Facilities (HCF) have in the management of Medical Equipments (ME), a Web system was proposed that would enable and simplify the deployment of control mechanisms in these institutions. The system is a platform to register the information about medical equipment of a $\mathrm{HCF}$, and it can be accessed from any terminal connected to the internet. The system follows the same principles of a Web service, such as the webmails, allowing the Health Care Facility create an account and have access to all management resources. The system was developed using HTML, CSS and JavaScript technologies to implement the client's interface. It is used PostgreSQL database, Node.js for server requests and JavaScript to control logic development of the service. The implementation of a System Management of Medical Equipments as a Web service is feasible and accessible for all different types Health Care Facilities.

Keywords: Medical Equipments, Clinical Engineering, Equipments Management, WEB System.

\section{Introdução}

A Agência Nacional de Vigilância Sanitária (ANVISA), por meio da RDC n. 02, de 25 de janeiro de 2010, define que todos os estabelecimentos de saúde devem realizar o gerenciamento das tecnologias em saúde utilizadas na prestação de seus serviços, desde sua entrada no estabelecimento até seu destino final, incluindo o planejamento dos recursos físicos, materiais e humanos [1].

$\mathrm{O}$ departamento de engenharia tem papel importante na gestão das tecnologias de saúde dentro das instituições, sendo que o sua atuação não se limita somente às intervenções das instalações ou reparo dos equipamentos, abrangendo funções de inventário, monitoramento do parque, treinamento, controle das manutenções, reposição de materiais e peças, incorporação de novas tecnologias, controle das calibrações, entre outras [2].

Segundo o Cadastro Nacional de Estabelecimentos de Saúde (CNES), o Brasil possuía em março de 2016 a quantidade de 287.750 estabelecimentos cadastrados [3]. Essa significativa quantidade de estabelecimentos levanta a questão de como é feita a gestão do parque tecnológico dos Equipamentos Médico-Hospitalares $(\mathrm{EMH})$ no país, principalmente ao se imaginar o diferente perfil dos diversos tipos Estabelecimentos Assistenciais de Saúde (EAS) existentes.

Um parâmetro que descreve bem a dimensão e importância do mercado de equipamentos e produtos médico-hospitalares é a estimativa de movimentação financeira em torno de US\$ 11 bilhões no ano de 2014 , entre importações e exportações, segundo dados da Associação Brasileira de Indústria de Alta Tecnologia de Produtos para Saúde (ABIMED) [4].

Durante a elaboração deste trabalho foi possível observar algumas iniciativas isoladas de desenvolvimento de sistemas de apoio à gestão de $\mathrm{EMH}$, principalmente em algumas instituições de maior porte, como por exemplo, o Sistema de Gerenciamento de Equipamentos (SGE) do Hospital de Clínicas de Uberlândia da Universidade Federal de Uberlândia (HCUFU) [5] e o Sistema de Gerenciamento de Informações de Equipamentos Médico-Hospitalares (GEM-HOS) desenvolvido no Hospital Universitário de Brasília (HUB) [6], além de algumas soluções comerciais, como o Philips Tasy Sistema de Gestão em Saúde e o TOTVS Hospitais, que englobam a gestão do ambiente 
hospitalar e apresentam módulos de apoio para gestão de equipamentos médico-hospitalares. Existem ainda alguns softwares de código aberto para a gestão da manutenção de equipamentos em geral, como o GLPI, que mesmo não sendo específico para a gestão de equipamentos médico-hospitalares e não contemplando todas as características desse tipo equipamento, mesmo assim é utilizado por alguns EAS. Estes sistemas nem sempre se mostram acessíveis ou adequados, principalmente para os EAS de menor porte, pois geralmente necessitam a aquisição e implantação de recursos de infraestrutura dedicados e que podem apresentar um custo elevado.

Neste contexto, a motivação deste trabalho foi desenvolver um sistema que permita a gestão dos EMH que possa ser utilizado pelos profissionais de engenharia clínicas dos mais diversos tipos de EAS, de pequenos a grandes, que esteja disponível via internet, sem a necessidade da implantação de qualquer infraestrutura auxiliar, que mantenha a segurança e integridade dos dados e seja de fácil operação.

\section{Materiais e métodos}

O desenvolvimento do sistema foi dividido basicamente em duas partes: cliente $W E B$ (com a interface do usuário) e o servidor (que recebe todas as requisições do serviço e armazena os dados).

Cliente WEB - A interface do cliente WEB foi desenvolvida utilizando-se HTML, CSS e a linguagem JavaScript. A adoção dessas tecnologias permite que o sistema seja utilizado da mesma forma a partir de qualquer navegador internet, nos vários sistemas operacionais como: Microsoft Windows, Android, Linux, iOS e Mac OSX.

Um recurso importante da interface cliente é a capacidade de adaptação automática às características dos dispositivos a partir dos quais o sistema está sendo acessado, isso permite a mesma experiência quando se opera o sistema a partir de computadores desktop, tablets ou smartphones.

Servidor - O servidor de aplicação utiliza como sistema gerenciador de banco de dados (SGBD) o PostgreSQL, que é um projeto de código aberto multiplataforma, que apresenta como principais características: segurança, flexibilidade, escalabilidade e alta performance [7].

Para atendimento das requisições foi utilizado o Node.js, que é um interpretador JavaScript capaz de manipular dezenas de milhares de conexões simultâneas. O Node.js é baseado no interpretador V8, desenvolvido e mantido pelo Google, e está disponível para vários sistemas operacionais [8]. Uma vantagem na opção do Node.js, como servidor de requisições, é utilizar JavaScript para desenvolvimento do cliente e do servidor, padronizando a escrita de código e permitindo que uma parte dele seja compartilhada entre os dois lados.

$\mathrm{O}$ armazenamento dos dados pode ser dividido em grupos funcionais, que descrevem informações relacionadas. A Tabela 1 apresenta os grupos funcionais básicos que compõem o sistema.

Tabela 1: Detalhes dos grupos funcionais de armazenamento de dados.

\begin{tabular}{lc}
\hline Grupo & Funcionalidade \\
\hline $\begin{array}{l}\text { Grupo 01 - Controle } \\
\text { de Acesso }\end{array}$ & Instituição e Usuário. \\
$\begin{array}{l}\text { Grupo 02 - Estrutura } \\
\text { das instituições }\end{array}$ & $\begin{array}{c}\text { Unidade, Setor, Sala e } \\
\text { Centro de Custo. }\end{array}$ \\
$\begin{array}{l}\text { Grupo 03 - Fabricantes } \\
\text { e Prestadores }\end{array}$ & $\begin{array}{c}\text { Fabricante, Modelo, } \\
\text { Princípio de funcionamento } \\
\text { e Prestadores de Serviço. }\end{array}$ \\
$\begin{array}{l}\text { Grupo 04-Detalhes } \\
\text { dos Equipamentontos Forma de }\end{array}$ & Aquisição, Tipo de \\
& Manutenção, Ordem de \\
& Serviço. \\
\hline
\end{tabular}

O projeto do banco de dados seguiu a modelagem relacional, sendo aplicadas todas as regras inerentes, além da implementação de todas as integridades referenciais, de forma a evitar qualquer inconsistência no armazenamento e recuperação das informações [9].

Arquitetura - A arquitetura do sistema seguiu o padrão de desenvolvimento MVC, que consiste em separar a estrutura dos programas em três camadas, conforme a Figura 1, que são: Model - camada de manipulação de dados, responsável pela escrita, leitura e validação dos dados; View - camada de interação com o usuário, responsável pela exibição dos dados; e Controller - camada que recebe as requisições do usuário e estabelece o a ligação entre o Model e o View [10].

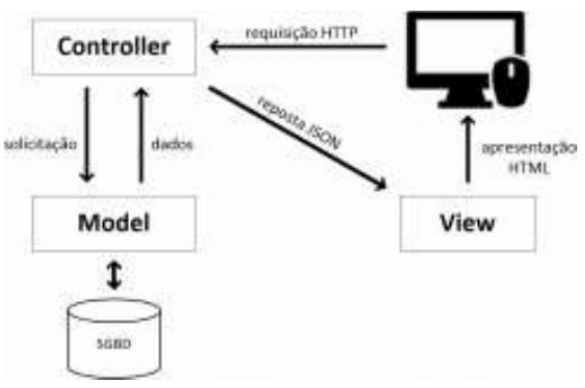

Figura 1: Arquitetura MVC adotada pelo do sistema. Fonte: Adaptado de Broski, C. [10]

\section{Resultados}

O sistema foi implantado em fase de teste em uma EAS de médio porte, com cerca de dois mil aparelhos geridos. Esta instituição utilizava o software livre GLPI, com algumas adaptações, para gestão do parque de equipamentos médico-hospitalares.

Durante os testes foram verificadas algumas diferenças cruciais entre o sistema proposto e o GLPI, tais como: obrigatoriedade de um cadastro detalhado dos equipamentos (com dados dos fabricantes e modelos), controles sobre calibração e manutenções 
preventivas, alertas para término da vida útil e descarte dos equipamentos, conforme descrito na legislação estabelecida pela ANVISA. Outra característica importante foi o acesso ao sistema a partir de dispositivos móveis, que agilizou o atendimento das ordens de serviços, reduziu a utilização de formulário impressos e permitiu que os gestores pudessem acompanhar as atividades da engenharia clínica, mesmo quando não estão presentes no EAS.

O sistema proposto disponibiliza um conjunto de recursos para cadastrar as informações necessárias para gestão dos EMH. Inicialmente é necessário criar uma conta no serviço, a partir dessa conta são cadastrados os dados que descrevem a estrutura da instituição, como: usuários, unidades que compõem a instituição, setores das unidades, salas dos setores e centro de custos. A interface de cadastramento segue o padrão conforme Figura 2 (smartphones) e Figura 3 (desktop e tablets).

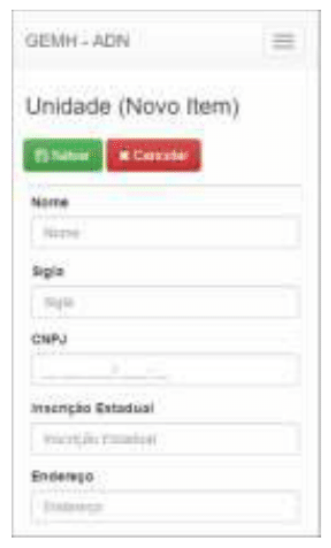

Figura 2: Interface de cadastramento de Unidade para smartphones.

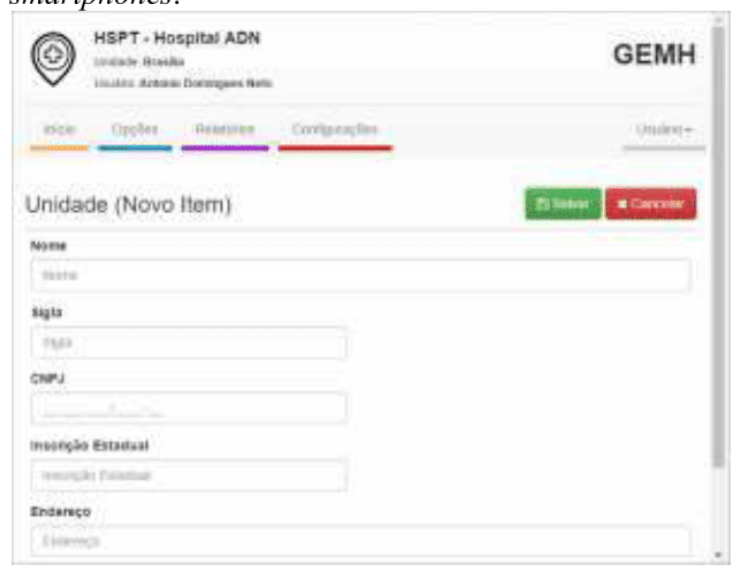

Figura 3: Interface de cadastramento de Unidade para desktop e tablets.

Para o cadastramento dos equipamentos é necessário informar os dados dos fabricantes e dos modelos. Após o registro de todas as informações básicas é possível cadastrar os equipamentos e a localização dos mesmos dentro da estrutura da instituição. A partir do cadastro de equipamentos torna-se disponível a abertura das ordens de serviço, onde são informadas as intervenções técnicas que podem ocorrer para cada equipamento.

Existe um conjunto de relatórios, que permite que o departamento de engenharia clínica da instituição extrair diversas informações, que vão desde o histórico de cada um dos equipamentos a uma visão geral da quantidade de manutenção, quantidades de equipamentos por setor, equipamentos que apresentam maior índice de defeito por fabricante e modelo, entre outros.

Outra possibilidade é a visualização sumarizada das informações em gráficos, conforme Figura 4 e Figura 5 , que oferece uma visão geral de forma rápida.

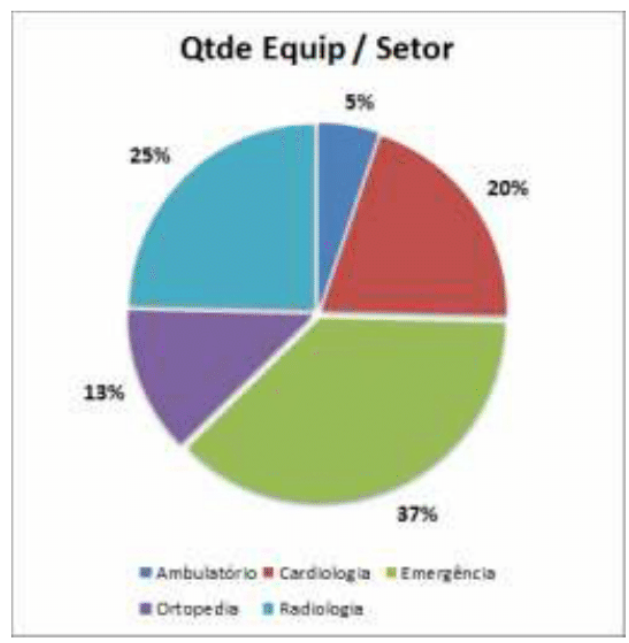

Figura 4: Gráfico da quantidade de equipamentos por setor.

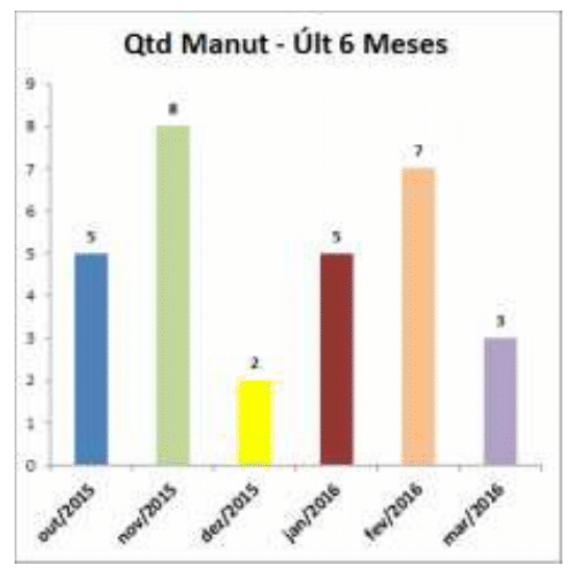

Figura 5: Gráfico da quantidade de manutenções nos últimos seis meses.

\section{Discussão}

A gestão do parque tecnológico dos equipamentos médico-hospitalares é uma necessidade dos EAS, estabelecida pela legislação em vigor. Com isso, sistemas de gestão informatizados se revelam uma 
ferramenta importante para implementação desta gestão.

Atualmente sistemas WEB têm se consolidados como uma opção viável para implementação de sistemas informatizados, reduzindo os custos de implantação e infraestrutura, além de permitir o acesso a partir de qualquer dispositivo conectado a internet, se adaptando automaticamente as características dos dispositivos.

Neste trabalho é proposto um sistema que oferece uma ferramenta para a gestão dos $\mathrm{EMH}$, onde qualquer instituição, independente do seu porte e sem a necessidade de investimento em infraestrutura, pode controlar seu parque tecnológico.

Para o desenvolvimento do sistema foi gerada uma base de dados de teste com: 250 instituições, cada instituição com 10 unidades e cada unidade com 300 equipamentos cadastrados, gerando uma base de dados com o total de 1.250 .000 equipamentos. Para esse volume de dados os tempos de reposta do servidor se mantiveram abaixo de $1 \mathrm{~s}$, para uma velocidade de conexão $15 \mathrm{MB} / \mathrm{s}$ no cliente, o que demostra que é viável o desenvolvimento do sistema como um serviço $W E B$

Com a possibilidade do uso do sistema a partir de dispositivos móveis os departamentos de engenharia clínica ganham agilidade e mobilidade na manipulação das informações dos EMH, como no processo de inventário do parque tecnológico e na consulta de relatórios e dados estatísticos.

O sistema está em fase de teste fechado, para validar as funcionalidades e o desempenho do sistema, sendo que poderá se proposto melhorias e novas características. Após a fase de teste a intenção é liberar o sistema para o uso das instituições de saúde em geral.

Uma das novas funcionalidades que estão sendo avaliada para futura implementação é o uso de etiquetas RFID (Identificação por Radiofrequência), conforme proposto por Cavalcante et.al. [11], simplificar e automatizar a localização dos equipamentos no ambiente hospitalar.

\section{Conclusão}

Considerando a importância da gestão dos EMH para as instituições de saúde, constata-se a necessidade de se automatizar este processo, principalmente devido ao grande volume de dados envolvidos e a agilidade que um sistema pode proporcionar aos departamentos de engenharia clínica dos EAS. Com o uso e validação do sistema, por algumas instituições, uma visão mais abrangente do impacto da automatização da gestão dos EMH estará disponível em publicações futuras.

\section{Referências}

[1] ANVISA, 2010. Disponível em: $<$ http://www20.anvisa.gov.br/segurancadopaciente /index.php/legislacao/item/rdc-2-de-25-de-janeirode-2010>. Acesso em: 01 março 2016.

[2] ANTUNES, E. et al. Gestão da Tecnologia Biomédica: Tecnovigilância e Engenharia Clínica. Paris: Acodess, 2002.

[3] CNES, 2016. Disponível em: $<\mathrm{http}: / /$ cnes2.datasus.gov.br/Lista_Tot_Es_Estado. asp>. Acesso em: 02 abril 2016.

[4] ABIMED, 2015. Disponível em: $<$ http://intranet.abimed.org.br/noticia.asp?id=435> . Acesso em: 01 março 2016.

[5] FARIA, V. et al. Desenvolvimento de software auxiliar à gestão de Equipamentos MédicoHospitalares utilizando Indicadores de Desempenho. IN: XXIV Congresso Brasileiro de Engenharia Biomédica - CBEB 2014. Uberlândia: Anais do CBEB 2014. v. 1. 2014. p. 2353-2356.

[6] LIMA, E. GEM-HOS - Sistema de Gerenciamento de Informações de Equipamentos Médico-Hospitalares. $O$ caso do Hospital Universitário de Brasília (HUB). Brasília: ENE/FT/UnB, 2008. 99 p. Dissertação de Mestrado - Universidade de Brasília, Faculdade de Tecnologia. Departamento de Engenharia Elétrica.

[7] DAR, U. et al. PostgreSQL Server Programming. 2nd Revised. ed. [S.1.]: Packt Publishing, 2015.

[8] HERRON, D. Node.JS Web Development. 3rd Revised. ed. [S.1.]: Packt Publishing, 2016.

[9] DATE, C. J. Projeto de Banco de Dados e Teoria Relacional. $1^{\mathrm{a}}$. ed. São Paulo: Novatec Editora, 2015.

[10] BROSKI, C. RESTful MVC. Berkley: Apress, 2016.

[11] CAVAlCANTE, E. L. et al. Sistema de Localização Informatizada de Equipamentos Médico-Hospitalares. IN: XXIV Congresso Brasileiro de Engenharia Biomédica - CBEB 2014. Uberlândia: Anais do CBEB 2014. v. 1. 2014. p. 2432-2435. 